\title{
Structure, dynamics and RNA binding of the multi-domain splicing factor TIA-1
}

\author{
Iren Wang ${ }^{1,2}$, Janosch Hennig ${ }^{1,2}$, Pravin Kumar Ankush Jagtap ${ }^{1,2}$, Miriam Sonntag ${ }^{1,2}$, \\ Juan Valcárcel ${ }^{3}$ and Michael Sattler ${ }^{1,2, *}$
}

${ }^{1}$ Institute of Structural Biology, Helmholtz Zentrum München, Ingolstädter Landstraße 1, 85764 Neuherberg, Germany, ${ }^{2}$ Center for Integrated Protein Science Munich and Biomolecular NMR, Department Chemie Technische Universität München, Lichtenbergstraße 4, 85747 Garching, Germany and ${ }^{3}$ Centre de Regulació Genòmica and Universitat Pompeu Fabra, Dr. Aiguader 88, 08003 Barcelona, Spain

Received November 27, 2013; Revised February 16, 2014; Accepted February 23, 2014

\begin{abstract}
Alternative pre-messenger ribonucleic acid (premRNA) splicing is an essential process in eukaryotic gene regulation. The T-cell intracellular antigen1 (TIA-1) is an apoptosis-promoting factor that modulates alternative splicing of transcripts, including the pre-mRNA encoding the membrane receptor Fas. TIA-1 is a multi-domain ribonucleic acid (RNA) binding protein that recognizes poly-uridine tract RNA sequences to facilitate $5^{\prime}$ splice site recognition by the U1 small nuclear ribonucleoprotein (snRNP). Here, we characterize the RNA interaction and conformational dynamics of TIA-1 by nuclear magnetic resonance (NMR), isothermal titration calorimetry (ITC) and small angle X-ray scattering (SAXS). Our NMRderived solution structure of TIA-1 RRM2-RRM3 (RRM2,3) reveals that RRM2 adopts a canonical RNA recognition motif (RRM) fold, while RRM3 is preceded by an non-canonical helix $\alpha 0$. NMR and SAXS data show that all three RRMs are largely independent structural modules in the absence of RNA, while RNA binding induces a compact arrangement. RRM2,3 binds to pyrimidine-rich FAS pre-mRNA or polyuridine (U9) RNA with nanomolar affinities. RRM1 has little intrinsic RNA binding affinity and does not strongly contribute to RNA binding in the context of RRM1,2,3. Our data unravel the role of binding avidity and the contributions of the TIA-1 RRMs for recognition of pyrimidine-rich RNAs.
\end{abstract}

\section{INTRODUCTION}

T-cell intracellular antigen-1 (TIA-1) is a ribonucleic acid (RNA)-binding protein that is implicated in alternative splicing regulation of various pre-messenger ribonucleic acid (pre-mRNA), with diverse functions of the proteins encoded such as in sex determination in Drosophila or apoptosis, homeostasis and survival of motor neurons in humans (1-3). Besides its role in alternative splicing, TIA-1 is able to mediate and suppress mRNA translation by binding to $3^{\prime}$ untranslated regions marked by AU-rich elements (AREs) in the cytoplasm during environmental stress (4-6). More recently, TIA-1 has also been implicated in translational control via binding to $5^{\prime}$ terminal oligopyrimidine-tract $\left(5^{\prime}\right.$ TOP) RNAs (7-8).

TIA-1 has been identified as an apoptosis-promoting factor that mediates programmed cell death by associating with the Fas-activated serine/threonine kinase (FAST-K) signal pathway (9). TIA-1 promotes the inclusion of exon 6 during splicing of human FAS pre-mRNA, which encodes a transmembrane protein that triggers programmed cell death. Alternative splicing by skipping of $F A S$ exon 6 results in a soluble anti-apoptotic form of the Fas protein that is linked to autoimmune responses (10) and systemic lupus erythematosus (11). Pre-mRNAs targeted for splicing regulation by TIA-1 harbor short uridine-rich (U-rich) stretches located downstream of $5^{\prime}$ splice sites (12-15). Upon binding to these U-rich RNA motifs the TIA-1/RNA complex promotes $5^{\prime}$ splice site recognition by U1 small nuclear ribonucleoprotein (snRNP) through the interaction with the U1 snRNP-associated protein U1C (12). Phosphorylation of TIA-1 by FAST-K has been shown to enhance the recruitment of U1 snRNP to promote the inclusion of $F A S$ exon 6 (16).

TIA-1 and its close homolog TIA-1-related protein, TIAR, have distinct expression patterns in different human tissues and cell lines (17-19). Both proteins are widely expressed in cells and mediate splicing of their own premRNA (19-20). Two human TIA-1 isoforms, TIA-1a and TIA-1b, show similar sub-cellular distribution and RNA binding activity. The TIA-1a isoform has a 11 amino acid insertion preceding RRM2, corresponding to a 386 residue protein. TIA-1b lacks this insertion and displays enhanced

\footnotetext{
*To whom correspondence should be addressed. Tel: +49 89 28913418; Email: sattler@helmholtz-muenchen.de

(C) The Author(s) 2014. Published by Oxford University Press on behalf of Nucleic Acids Research.

This is an Open Access article distributed under the terms of the Creative Commons Attribution License (http://creativecommons.org/licenses/by-nc/3.0/), which permits non-commercial re-use, distribution, and reproduction in any medium, provided the original work is properly cited. For commercial re-use, please contact journals.permissions@oup.com
} 
splicing stimulatory activity compared to TIA-1a both in vitro and in vivo (19). As the biological role of TIA-1b has been well characterized by previous studies the present study focuses on TIA-1b, which will be referred to as TIA1 from now on. TIA-1 encompasses 375 amino acids and consists of three RNA recognition motifs (RRM1, RRM2 and RRM3) and a C-terminal glutamine-rich domain (Qrich domain) (Figure $1 \mathrm{~A}$ and $\mathrm{B}$ ), and the sequence alignment from different species are compared and aligned by ClustalW2 (21) and by ESPript (22-23). In vitro binding studies indicate that the three TIA-1 RRM domains have different capacities to bind RNA $(12,17,24-25)$. The central TIA-1-RRM2 exhibits highest binding affinity towards pre-mRNA targets but RNA binding is further enhanced by the presence of RRM3. A recent study suggested a potential $\mathrm{pH}$-dependent regulation of binding to AU-rich RNAs involving a histidine residue in an N-terminal extension of RRM3 (25). In contrast, TIA-1-RRM1 is thought to assist the Q-rich domain to recruit the U1 snRNP-associated protein U1C by protein-protein interactions (12).

Recently, individual-nucleotide resolution UVcrosslinking and immunoprecipitation (iCLIP) experiments have mapped the regions of TIA-1 binding to pre-mRNA transcripts. The most frequent TIA-1 binding sites are observed 10-28 nucleotides downstream of exon/intron boundaries (26). A corresponding region downstream of the $5^{\prime}$ splice site of FAS intron 5 is thus relevant for studying the protein-RNA interaction of TIA-1 (Figure 1C). The presence and interactions with U1-C and the base pairing of the U1 snRNA with the $5^{\prime}$ splice site likely influences the binding of TIA-1 to the pre-mRNA. Not only uridine-rich stretches downstream but also upstream of an exon mediate TIA-1 binding (2).

TIA-1 is a typical multi-domain RNA binding protein where individual RNA binding domains connected by flexible linkers cooperate in the recognition of target RNAs. Understanding the contributions and interplay of the individual domains is required to dissect the molecular mechanisms of TIA-1 in the regulation of the Fas signal transduction pathway and apoptosis. So far, only experimentally determined structures of the unbound TIA-1 RRM2 domain have been reported by crystallography and NMR (27-28), which showed that RRM2 adopts a canonical RRM fold. The relative contributions and arrangements of the three RRM domains and their role for RNA recognition are not known. Using isothermal titration calorimetry (ITC) experiments, Kielkopf et al. have recently demonstrated that FAS intron 5 RNA exhibits two binding sites with comparable affinities for TIA-1, and proposed that all three RRMs contribute to high affinity binding to a poly-uridine RNA (U20) (24). However, the sequence motifs recognized in the $F A S$ intron 5 RNA and molecular details are unknown.

Here, we have combined solution state NMR, ITC and small angle X-ray scattering (SAXS) experiments to study the structure, dynamics and RNA binding of TIA-1. NMR relaxation data and chemical shift comparisons indicate that, in the absence of RNA, the three RRMs of TIA-1 are independent structural modules connected by flexible linkers. The solution structure of a tandem RRM2,3 construct of TIA-1 (TIA-1-RRM2,3) reveals that RRM3 is unusual as it represents a canonical RRM fold that is extended by an $\mathrm{N}$-terminal helix $\alpha 0$, consistent with previous secondary structure analyses (29). While RRM2 and RRM3 tumble independent from each other in the absence of RNA a uniform rotational correlation time is observed when bound to an RNA ligand derived from FAS pre-mRNA intron 5. SAXS analysis of RRM2,3 bound to this intron RNA ligand further demonstrates that the protein-RNA complex is rigid and compact - in contrast to the free protein. A similar compaction of the overall domain arrangements is also found for RRM1,2,3 upon binding to a U15 RNA ligand. NMR and ITC experiments reveal that TIA-1-RRM2,3 has two binding sites for a 16-mer FAS intron RNA and binds with 1:1 stoichiometry and nanomolar affinity to a 10-mer derived from the FAS intron RNA or to a U9 oligonucleotide. RRM1 has little intrinsic RNA binding affinity and does not strongly contribute to U15 RNA binding in the context of RRM1,2,3. Our results show that the multiple RRM domains of TIA-1 are structural independent modules in the absence of RNA, while RRM2,3 bind cooperatively to pyrimidine-rich RNA ligands.

\section{MATERIALS AND METHODS}

\section{Sample preparation}

Several TIA-1 constructs including RRM1 (residues 192), RRM2 (residues 93-175), RRM3 (residues 195-274), RRM2,3 (residues 93-274) and RRM1,2,3 (residues 1-274) were selected according to previously described studies (12). The amplified DNA fragments were sub-cloned into the expression vector pETtrx_1a vector (European Molecular Biology Laboratory, Heidelberg, Germany) between NcoI and KpnI sites, as a fusion with an N-terminal His-tag, a thioredoxin fusion tag and a TEV protease cleavage site. An N-terminal extension construct of RRM3 named RRM3 (residues 187-274) was made to have a complete RRM3 domain of TIA-1 by insertion into a modified pETM-11 vector, including an N-terminal His-tag, a Z-tag and separated by a TEV protease cleavage site. All recombinant proteins were transformed into Escherichia coli strain BL21 (DE3), except for RRM1, which was transformed into $E$. coli strain Rosetta (DE3) for expression. Unlabeled, ${ }^{15} \mathrm{~N}$ uniformly labeled, or ${ }^{15} \mathrm{~N} /{ }^{13} \mathrm{C}$ uniformly labeled protein samples were expressed by growing cells in Luria-Bertani (LB) medium or M9 minimal medium (kanamycin $30 \mu \mathrm{g} \cdot \mathrm{ml}^{-1}$ ) supplemented with ${ }^{15} \mathrm{NH}_{4} \mathrm{Cl}$ and ${ }^{13} \mathrm{C}$-glucose at $20^{\circ} \mathrm{C}$ overnight after induction at $\mathrm{OD}_{600}$ of $0.6-0.8$ with $0.5 \mathrm{mM}$ IPTG. The cells were harvested by centrifugation and resuspended in buffer containing $50 \mathrm{mM}$ sodium phosphate $(\mathrm{pH} 8.0)$ and $300 \mathrm{mM} \mathrm{NaCl}$. The harvested cells were disrupted using a homogenizer (Microfluidics), and cell lysate and supernatant were separated by centrifugation at $45000 \times g$ for 30 min at $4{ }^{\circ} \mathrm{C}$. The supernatant protein was bound to Ni-NTA resin (Qiagen) and subsequently washed by buffer with 10 and $20 \mathrm{mM}$ imidazole, respectively to remove most protein impurities, and then eluted with the same buffer containing $120 \mathrm{mM}$ imidazole. Eluted protein was incubated with TEV protease at room temperature overnight for fusion tag removal. After buffer exchange to remove imidazole, a second Ni-NTA affinity column was applied to separate solubility tags from the tag free protein products. The tag free 
(A)

TIA-1

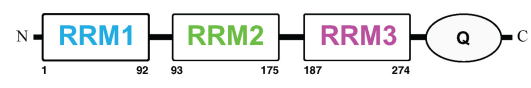

(B)
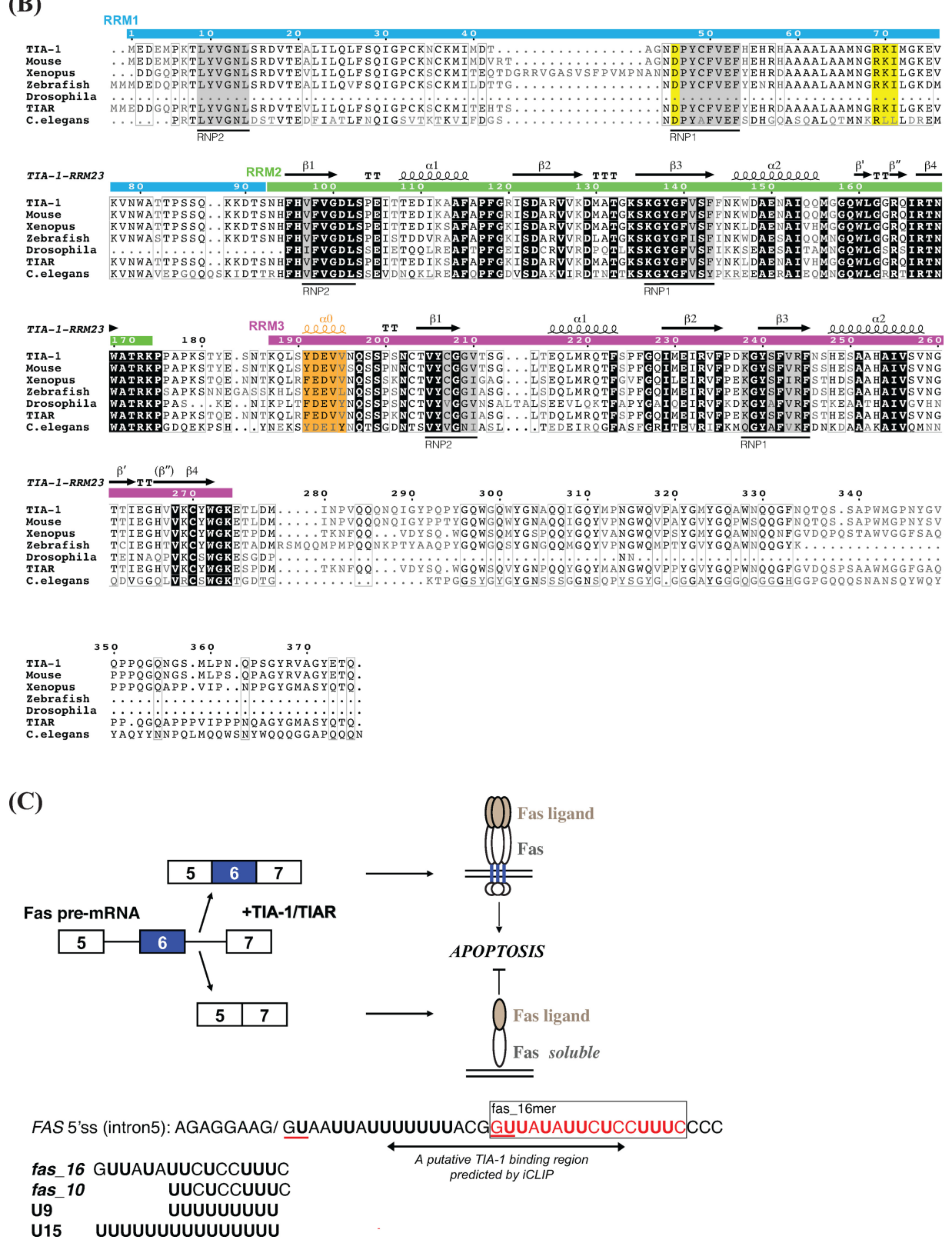

Figure 1. (A) Schematic representation of human TIA-1 domains. (B) Sequence alignment of TIA-1 and TIAR from different species. Original sequences used in the analysis: residues 1-375 of Homo sapiens TIA-1, residues 1-377 of Mus musculus TIA-1, residues 41-427 of Xenopus laevis TIA-1, residues 1-342 of Danio rerio (zebrafish) TIA-1, residues 166-356 of Drosophila melanogaster TIA-1, residues 1-375 of Homo sapiens TIAR and residues 45-373 of Caenorhabditis elegans TIAR are compared and aligned by ClustalW2 (21) and plotted by ESPript $2.2(22,23)$. The secondary structure indicated corresponds to the solution structure of human TIA-1-RRM2,3. The RNP1 and RNP2 motifs are highlighted with gray background, the negatively charged residue in RNP1 and the RXI/V/L motif of RRM1 indicative of a potential UHM domain are shown with yellow background. The residues in RRM3 helix $\alpha 0$ are colored orange. (C) Alternative splicing of human $F A S$ exon 6 . The putative TIA-1 binding region in $F A S$ intron 5 indicated by a double-arrow is predicted by iCLIP analyses, i.e. 10-28 nucleotides downstream of exon/intron boundaries. The GU motifs corresponding to $5^{\prime}$ splice sites in FAS intron 5 RNA are underlined in red. RNA sequences of the 16-mer pre-RNA ligand in FAS intron5 (fas_16) and a uridine-rich RNA (U9), used in the present study are indicated. 
TIA-1 fragment was then purified by size-exclusion chromatography (HiLoad 16/60 Superdex 75, GE Healthcare Biosciences). The purity of the subsequent eluted protein was detected on a Coomassie-blue-stained sodium dodecyl sulfate (SDS) polyacrylamide gel (PAGE) and shown to be higher than $95 \%$. RNA oligonucleotides used for NMR and ITC were purchased from Biospring GmbH, Frankfurt (Germany) and/or IBA GmbH, Göttingen (Germany). The final concentration of TIA-1 fragments and RNA were checked by absorbance at 280 and $260 \mathrm{~nm}$, respectively, using a NanoDrop 1000 spectrophotometer (Thermo Scientific).

\section{NMR spectroscopy}

Spectra were acquired at $298 \mathrm{~K}$ using a AVIII500, AVIII600, AVIII750, AVIII800 and a AVI900 Bruker NMR spectrometer, equipped with cryogenic or room temperature $(750 \mathrm{MHz})$ triple resonance gradient probes. Samples contained $0.1-0.7 \mathrm{mM}$ protein in $10 \mathrm{mM}$ sodium phosphate (pH 6.5), $50 \mathrm{mM} \mathrm{NaCl}, 10 \mathrm{mM}$ DTT, $0.02 \% \mathrm{NaN}_{3}$ with $10 \%{ }^{2} \mathrm{H}_{2} \mathrm{O}$ added for the lock. All spectra were processed using NMRPipe/Draw (30) and analyzed using Sparky (31) and NMRView (32). Protein backbone assignments for ${ }^{15} \mathrm{~N},{ }^{1} \mathrm{H}^{\mathrm{N}},{ }^{13} \mathrm{C}^{\alpha},{ }^{13} \mathrm{C}^{\beta}$ and ${ }^{13} \mathrm{C}^{\prime}$ chemical shifts were obtained from HNCACB, CBCA(CO)NH, HNCA and HNCO experiments (33). Amino acid side chain resonance assignments were obtained from standard HCCH-TOCSY, $\mathrm{HBHA}(\mathrm{CO}) \mathrm{NH}(34),{ }^{15} \mathrm{~N}$ - and ${ }^{13} \mathrm{C}$-edited NOESY-HSQC experiments. Aromatic resonances were assigned using $2 \mathrm{D}$ ${ }^{1} \mathrm{H}-{ }^{13} \mathrm{C}$ HSQC, HBCBCGCDHD, HBCBCGCDCEHE (35) and NOESY spectra.

\section{NMR relaxation measurements}

To study the dynamical properties of protein free and bound with RNA, NMR data were recorded at $298 \mathrm{~K}$ for 0.15 $\mathrm{mM}$ of TIA-1-RRM1,2,3 and $0.55 \mathrm{mM}{ }^{15} \mathrm{~N}$-labeled TIA1-RRM2,3 protein free and bound to fas_l6 RNA (ratio $1: 2$ of protein to RNA) on a $750 \mathrm{MHz}$ NMR spectrometer at $298 \mathrm{~K}$, while data for $0.2 \mathrm{mM}{ }^{15} \mathrm{~N}$-labeled TIA-1RRM1,2,3 bound with U15 RNA (ratio 1:1.2 of protein to RNA) were acquired on a $800 \mathrm{MHz}$ Bruker NMR spectrometer. Amide ${ }^{15} \mathrm{~N}$ relaxation data of $R_{1}, R_{1 \rho}$, and steadystate heteronuclear $\left\{{ }^{1} \mathrm{H}\right\}-{ }^{15} \mathrm{~N}-\mathrm{NOE}$ experiments were performed as described (36-37). $R_{1}$ data were measured with 10 different relaxation delays, 21.5, 86.5, 162, 248.4, 518.4, $669.6,885.6,1144.8,1382.4$ and $2160 \mathrm{~ms}$, and $R_{1 \rho}$ data were determined by using nine delay points of $5,15,25,40$, $55,80,110,140$ and $200 \mathrm{~ms}$ for RRM2,3, RRM2,3 bound to fas_l6 RNA and free RRM1,2,3. For relaxation data recorded by RRM1,2,3 bound to U15: $R_{1}$ data were measured with 13 different relaxation points and three redundant delays, 21.6/21.6, 43.2, 86.4, 172.8, 259.2, 345.6/345.6, $518.4,669.6 / 669.6,885.6,1080,1296,1512$ and $1728 \mathrm{~ms}$, and $R_{1 \rho}$ data were determined by using 10 different delay points together with two redundant delays of $5 / 5,10,15$, 20, 30, 40, 50, 60, 80/80 and $100 \mathrm{~ms}$. Duplicate time points were used for error estimation. The transverse relaxation rate $R_{2}$ for each residue was estimated by correction of the observed relaxation rate $R_{1 \rho}$ with the offset $\Delta v$ of the rf field to the resonance using the relation $R_{1 \rho}=R_{1} \cos ^{2} \theta+R_{2}$ $\sin ^{2} \theta$, where $\theta=\tan ^{-1}\left(v_{1} / \Delta v\right)$. The correlation time $\left(\tau_{\mathrm{c}}\right)$ of the protein molecule was then estimated using the ratio of averaged $R_{2} / R_{1}$ values (38). Steady-state heteronuclear $\left\{{ }^{1} \mathrm{H}\right\}-{ }^{15} \mathrm{~N}-\mathrm{NOE}$ spectra were recorded with and without $3 \mathrm{~s}$ of ${ }^{1} \mathrm{H}$ saturation. All relaxation experiments were acquired as pseudo-3D experiments and converted to $2 \mathrm{D}$ data sets during processing. The relaxation rates and error calculations were determined by using Sparky. The relaxation data of the resonances of Phe ${ }^{95}-\mathrm{Leu}^{102}$ in RRM1,2,3 could not be analyzed because the amide signals are not observed.

\section{Small angle $X$-ray scattering experiments}

$30 \mu 1$ of TIA-1-RRM2,3 (with and without fas_16 RNA) complex sample and buffer were measured at $25^{\circ} \mathrm{C}$ at the BioSAXS beamline BM29 at the European Synchrotron Radiation Facility (ESRF) in Grenoble, France, using a 2D Pilatus detector. Ten frames with $2 \mathrm{~s}$ exposure time per frame were recorded for each complex and buffer sample, using an X-ray wavelength of $\lambda=1.008 \AA$. Measurements were performed in flow mode where samples were pushed through the capillary at a constant flow rate to minimize radiation damage. Frames showing radiation damage were removed prior to data analysis.

\section{SAXS data reduction and integral parameters}

For SAXS data collection and processing, the dedicated beamline software BsxCuBE was used in an automated fashion. The 1D scattering intensities of samples and buffers were expressed as a function of the modulus of the scattering vector $Q=(4 \pi / \lambda) \sin \theta$ with $2 \theta$ being the scattering angle and $\lambda$ the $\mathrm{X}$-ray wavelength. Buffer intensities were subtracted from the respective sample intensities using PRIMUS (39). The radii of gyration $R_{\mathrm{g}}$ of all samples were extracted by the Guinier approximation with the same program. The validity of the Guinier approximation, $R_{\mathrm{g}}$ for $Q$ $<1.3$, was verified and fulfilled in each case. $R_{\mathrm{g}}$ was also calculated as well as $D_{\max }$ from pairwise distribution functions using GNOM (40). All statistics are summarized according to Jacques et al. (41) in Supplementary Table S1.

\section{Structure calculation and validation}

Automated assignments for the cross-peaks of ${ }^{15} \mathrm{~N}$ - and ${ }^{13} \mathrm{C}$-edited NOESY-HSQC spectra and structure calculations with torsion angle dynamics were done by using the program CYANA 3.0 (42). The set of NOE distance restraints derived from CYANA as well as the $\varphi$ and $\psi$ backbone dihedral angle restraints derived from TALOS+ (43) based on the chemical shifts were used for molecular dynamics simulated annealing and water refinement by using the program of RECOORD (44). The hydrogen bonding restraints are applied based on the identification of slow $\mathrm{H} / \mathrm{D}$ exchange of amide protons by recording ${ }^{1} \mathrm{H},{ }^{15} \mathrm{~N}$ HSQC NMR spectra of lyophilized protein after redisolving in $100 \% \mathrm{D}_{2} \mathrm{O}$. All structures were validated by using iCing (45). Molecular images were generated with PyMol (Schrödinger) and MOLMOL (46). 


\section{NMR titrations}

${ }^{1} \mathrm{H},{ }^{15} \mathrm{~N}$ HSQC spectra of TIA-1-RRM2,3 titrated with fas_16 and U9 RNA ligands were carried out to map the RNA-binding region of the complex. $0.1 \mathrm{mM}{ }^{15} \mathrm{~N}$-labeled TIA-1-RRM2,3 was titrated with increasing amounts of RNA with various ratios of RNA to protein ranging from $0.2,0.4,0.6,0.8,1.0,1.2,1.4$ and 2.0 with fas_l6, 0.05, 0.1, $0.2,0.3,0.4,0.8$ and 1.25 with $\mathrm{U} 9$, and $0.2,0.4,0.6,0.8$, $1.0,1.2,1.4$ and 2.0 with fas_lo RNA. Similarly, $0.1 \mathrm{mM}$ of ${ }^{15}$ N-labeled TIA-1 RRM1,2,3 was titrated with increasing amounts of U15 RNA (0.1, 0.2, 0.4, 0.8 and 1.2 ratios). All measurements were acquired on a $600 \mathrm{MHz}$ Bruker NMR spectrometer at $298 \mathrm{~K}$ using the NMR buffer described above. RNA oligonucleotides used for NMR titration were purchased and used directly by dissolving in a small amount of buffer without further purification. No $\mathrm{pH}$ change was observed for the protein sample after RNA addition.

\section{Isothermal titration calorimetry}

All titrations were carried out using MicroCal iTC200 calorimeters (Microcal, Northhampton, USA) at $25^{\circ} \mathrm{C}$. To be consistent with the condition used for structural study, protein samples were dialyzed against NMR buffer without DTT to decrease noise. Buffer from the dialysis was used to resolubilize the RNA (BioSpring GmbH, Frankfurt, Germany) and to provide a baseline as required. The concentrations of 10 and $20 \mu \mathrm{M}$ fas_16 and U9 RNA were used to be titrated with 150-200 $\mu \mathrm{M}$ TIA-1-RRM2,3, respectively. The reverse titrations were performed using 70$75 \mu \mathrm{M}$ fas_l6 and/or U9 RNA adding into $10 \mu \mathrm{M}$ TIA-1RRM2,3. Similar titrations were performed with RRM2,3 and fas_10 (concentrations used: $577 \mu \mathrm{M}$ protein into 30 $\mu \mathrm{M}$ RNA and $58 \mu \mathrm{M}$ protein with $300 \mu \mathrm{M}$ RNA for reverse titration). For ITC measurements of RRM1,2,3 and U15, $300 \mu \mathrm{M}$ U15 RNA were used to titrate into $30 \mu \mathrm{M}$ TIA$1-\mathrm{RRM} 1,2,3$, and the reversed titration was by $\sim 170 \mu \mathrm{M}$ TIA-1-RRM1,2,3 adding into $15 \mu \mathrm{M}$ U15 RNA. For each titration of RRM2,3 with fas_16 or U9, 26 injections of 1.5 $\mathrm{ml}$ of titrant were made at $180 \mathrm{~s}$ injection intervals, and data were collected at $25^{\circ} \mathrm{C}$ while stirring at 1000 revolutions per minute (rpm). Data were reduced with heat spikes from control experiments, where protein or RNA was titrated into buffer. Raw data were integrated and normalized using Origin ITC Analysis software provided by Microcal. Accordingly, a plot of $\Delta H$ per mole of injection versus molar ratio was produced and fit to an appropriate binding model (onesite or two-sites binding). Measurements have been repeated at least twice.

\section{RESULTS}

The three RRMs of TIA-1 are independent structural modules

A superposition of ${ }^{1} \mathrm{H},{ }^{15} \mathrm{~N}-\mathrm{HSQC}$ spectra of the individual RRM domains and the $31 \mathrm{kDa}$ RRM1,2,3 region of TIA-1 is shown in Figure 2A. The chemical shifts of the NMR signals in the individual RRMs are very similar compared with the RRM1,2,3 protein construct. Interestingly, several residues (Lys ${ }^{146}$, Asp $^{148}$ and Glu ${ }^{150}$ ) in RRM2 helix $\alpha 2$ show significantly different chemical shifts in RRM1,2,3 when compared to the single RRM2 domain. These differences are not observed for the tandem RRM2,3 construct (Figure 2B). Charged residues $\left(\mathrm{Lys}^{88}\right.$ and $\mathrm{Lys}^{89}$ ) in the RRM1-RRM2 linker also exhibit notable chemical shift differences in RRM1,2,3, suggesting that this linker may contact RRM2 helix $\alpha 2$ via charge-charge interactions. Except from these differences chemical shifts of the isolated domains and RRM1,2,3 are very similar. Also in the RRM2,3 tandem domain construct only very minor chemical shift variations are found (Ile ${ }^{111}, \mathrm{Ala}^{114}, \mathrm{Phe}^{118}$, $\mathrm{Phe}^{140}$ in RRM2 and Val ${ }^{210}$ in RRM3) when compared with the single domains (Figure 2B). These data indicate that the individual RRM domains in RRM2,3 and RRM1,2,3 are largely independent structural modules and lack strong domain-domain interactions. It is noteworthy that a few cross-peaks from a short RRM3 construct (residues 195274 , comprising the predicted canonical RRM secondary structure) have different chemical shifts when compared with the tandem RRM2,3 (Supplementary Figure S1). Secondary ${ }^{13} \mathrm{C}$ chemical shifts (Supplementary Figure S2A) indicate that this region adopts an additional $\alpha$-helix preceding residue 195 of the canonical RRM3 domain. Thus, the canonical RRM fold is extended by an additional helix and the fold of RRM3 and comprises residues 187-274, consistent with recent predictions (29). Average rotational correlation times $\left(\tau_{\mathrm{c}}\right)$ were estimated for the individual domains from the trimmed mean ratio of ${ }^{15} \mathrm{~N} R_{2} / R_{1}$ relaxation rates for RRM1,2,3 (Figure 2C), assuming isotropic rotational diffusion. This analysis shows similar $\tau_{\mathrm{c}}$ values ( $\sim 12 \mathrm{~ns})$ for RRM1 and RRM3 but significantly larger $\tau_{\mathrm{c}}$ values $(\sim 16 \mathrm{~ns})$ for $\mathrm{RRM} 2$. A rotational correlation time of $\sim 15 \mathrm{~ns}$ would be expected for a $31 \mathrm{kDa}$ protein, if the three RRMs would tumble together. Smaller $\tau_{\mathrm{c}}$ values are expected if the individual RRMs do not interact strongly even though the rotational diffusion of the individual domains will still be coupled in spite of the presence of flexible linkers of 10 or more residues (47). The observation of distinct average $\tau_{\mathrm{c}}$ values for residues in RRM2 compared with RRM1 and RRM3 and the virtual identical chemical shifts observed for the individual domains compared with the RRM1,2,3 multi-domain construct demonstrate that the individual RRMs tumble independently from each other and that there are no strong domain interactions in the free TIA-1 protein.

NMR relaxation data of the TIA-1 RRM2,3 tandem domains and virtually identical chemical shifts of the individual RRM2 and RRM3 domains compared with RRM2,3 indicate that also in this fragment the individual domains tumble independently with no significant domain-domain interactions between RRM2 and RRM3 in absence of RNA (see below).

\section{Solution structure of TIA-1 RRM2,3}

To understand the role of RRM3 in enhancing the RNA binding affinity of RRM2 (12), we determined the NMRderived solution structure of the tandem TIA-1-RRM2,3 domains. The ensemble of the 10 lowest energy structures of TIA-1 RRM2,3 after water refinement is shown in Figure 3A, structural statistics are summarized in Table 1. As 
(A)

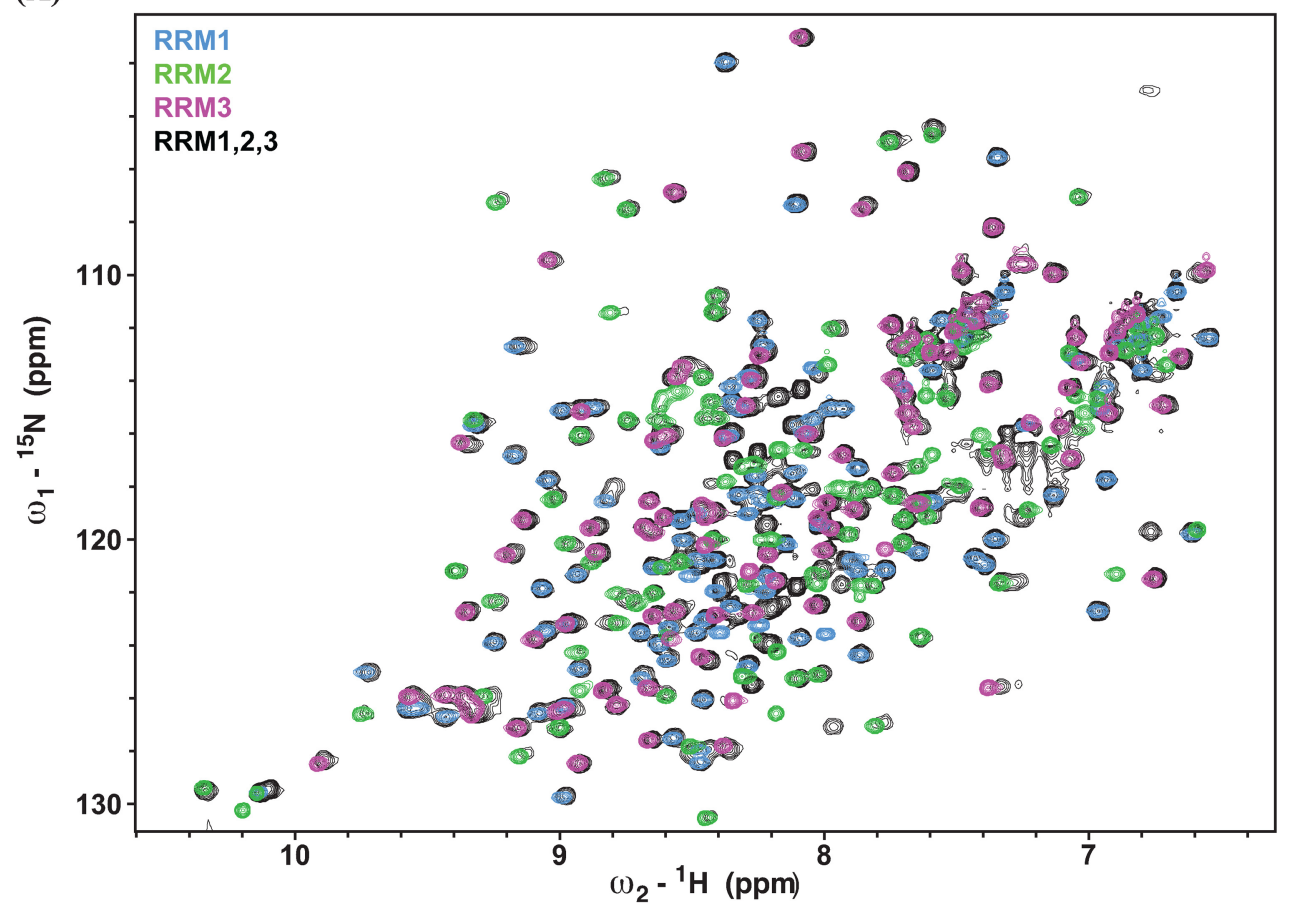

(B)

RRM1

RRM2

RRM3
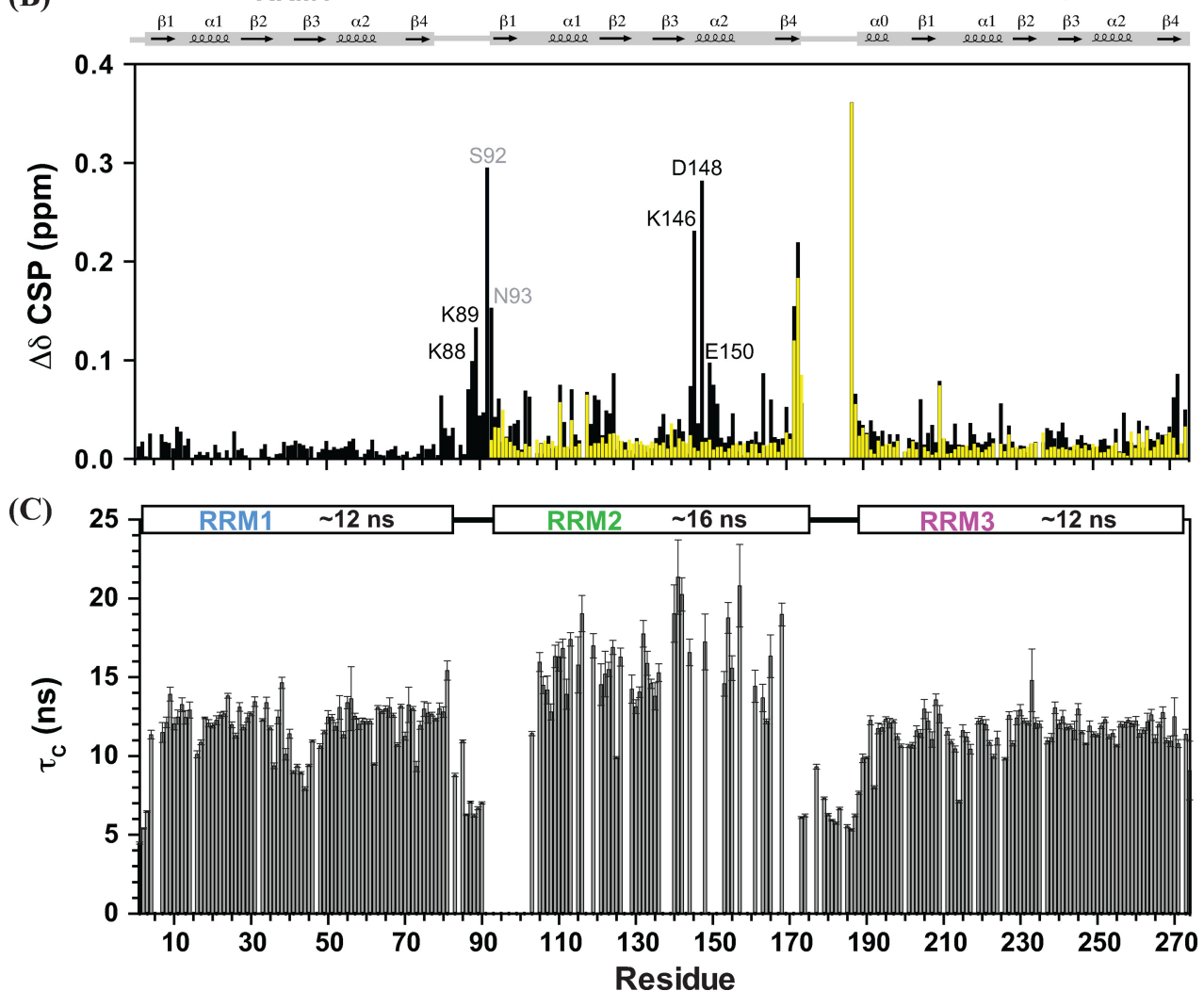

Figure 2. (A) The ${ }^{1} \mathrm{H},{ }^{15} \mathrm{~N}$ HSQC NMR spectra of individual RRM1 (blue), RRM2 (green), RRM3 (magenta) and RRM1,2,3 (black) are shown. (B) Differences of chemical shifts of individual RRM with RRM1,2,3 (black) and with RRM2,3 (yellow) are plotted versus residue number. Some distinct differences are observed in the RRM2 helix $\alpha 2$ (Lys ${ }^{146}$, Asp ${ }^{148}$ and $\mathrm{Glu}^{150}$ ) when compared with the resonances of RRM1,2,3. Residues in the RRM1-2 linker $\left(\mathrm{Ser}^{92}\right.$ and $\left.\mathrm{Asn}^{93}\right)$ and two predicting residues $\left(\mathrm{Lys}^{88}\right.$ and $\left.\mathrm{Lys}^{89}\right)$ also exhibit large chemical shift differences, suggesting that charge complementary interactions may contribute to the contacts of the RRM1-2 linker and RRM2. (C) Local rotational correlation times $\left(\tau_{\mathrm{c}}\right)$ estimated from the ratio of ${ }^{15} \mathrm{~N} R_{2} / R_{1}$ relaxation rates of RRM1,2,3 versus residue number are shown, with average $\tau_{\mathrm{c}}$ values for each RRM domain indicated above. Error bars are derived from the relaxation data. 
(A)
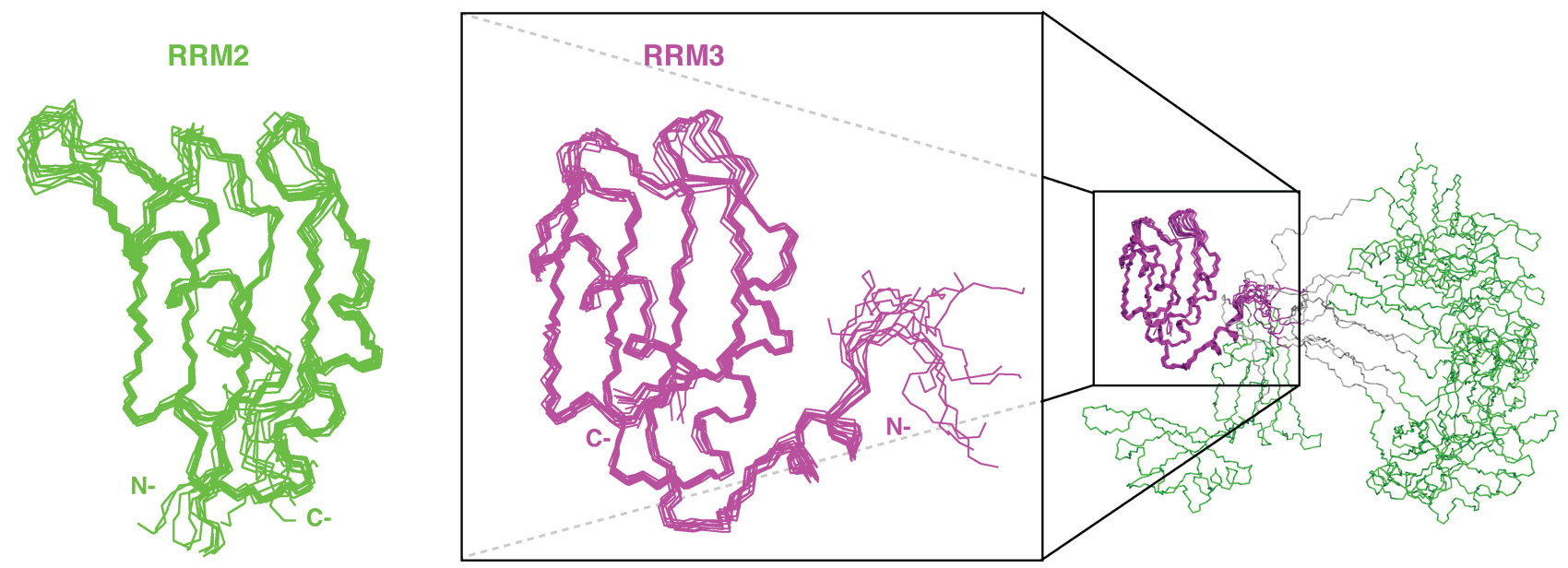

(B)
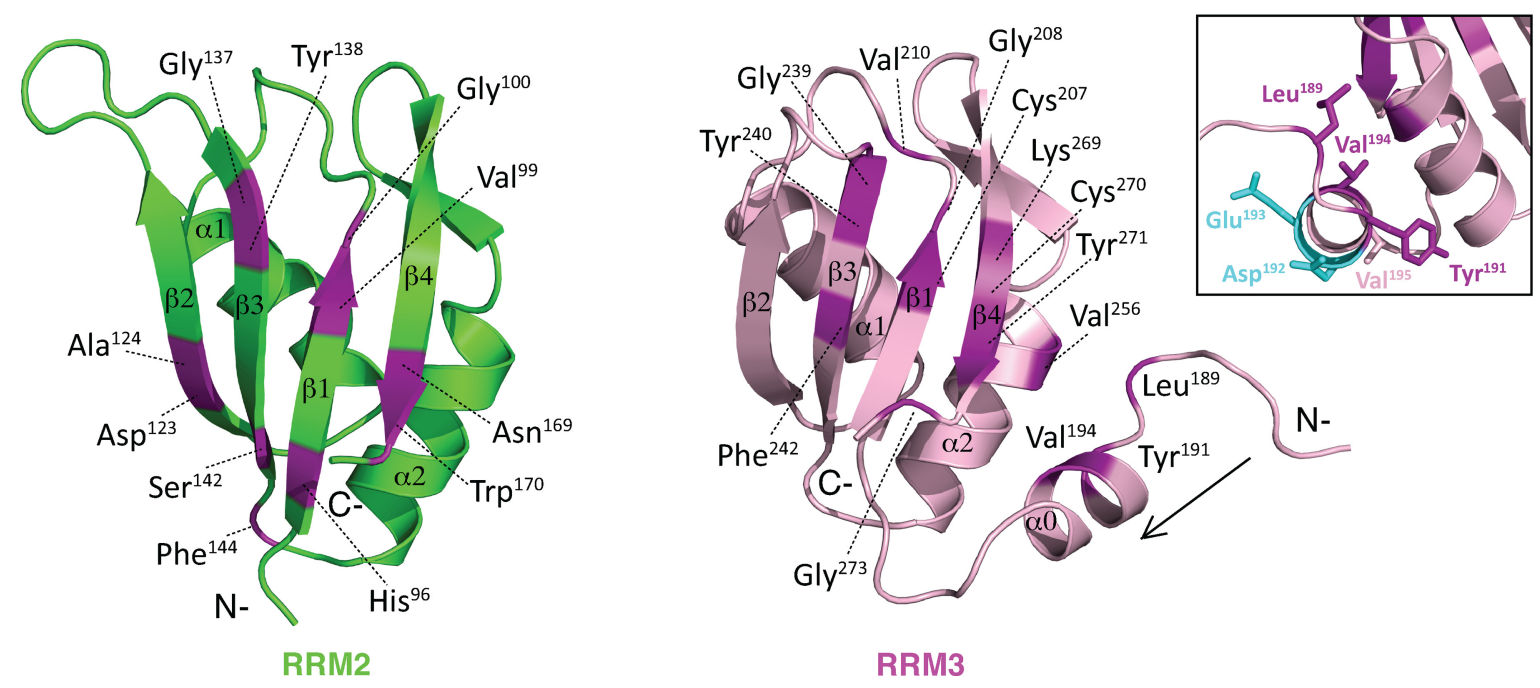

Figure 3. (A) The ensemble of the lowest 10 energy structures of TIA-1-RRM2,3 generated by superposition of backbone atoms of RRM 2 (residue 93-173, left) and RRM3 (residue 184-274, right) domains, respectively. The insert illustrates that the two domains do not interact, with residues in the RRM2-RRM3 linker colored in gray. (B) TIA-1-RRM2,3 ribbon representation of RRM2 and RRM3. Residues with exhibit significant chemical shift perturbation upon titration of RRM2,3 with fas_16 RNA are colored purple and annotated $(\Delta \delta>0.16$ ppm, average chemical shift perturbation over all resonances with standard deviation ()). The CSPs reveal that for both RRM2 and RRM3 residues in the RNP2 (VFVGDL/VYCGGV) and RNP1 (KGYGFVSF/KGYSFVRF) motifs ( $\beta 1$ and $\beta 3$ strands), as well as additional conserved residues in $\beta 4$ are involved in RNA binding. The inset shows side chains of residues in RRM3 helix $\alpha 0$ (YEDVV) with the orientation along the arrow. Solvent exposed acidic side chains of Asp ${ }^{192}$ and Glu ${ }^{193}$ are colored in cyan. The side chains of Leu ${ }^{189}, \mathrm{Tyr}^{191}$ and Val ${ }^{194}$ pack against RRM3 helix $\alpha 2$.

indicated by chemical shift analysis and NMR relaxation data the two domains do not interact, consistent with the absence of inter-domain NOEs. Therefore, the two RRM domains are presented and analyzed here individually (Figure 3B). RRM2 adopts the canonical $\beta \alpha \beta \beta \alpha \beta$ RRM fold composed of a four-stranded anti-parallel $\beta$-sheet covered on one side by two $\alpha$-helices. The structure of RRM 2 in the RRM2,3 protein resembles that of the isolated TIA-1 RRM2 domain reported previously (27-28), with backbone coordinate RMSDs of $0.91 \pm 0.08$ and $0.81 \pm 0.05 \AA$ to the RRM2 structure determined by NMR (PDB: 2RNE) and crystallography (PDB: 3BS9), respectively. RRM3 in RRM2,3 superimposes with the structure of the isolated RRM3 of the homologous TIAR protein (PDB: 1X4G) with a backbone coordinate RMSD of $0.79 \pm 0.06 \AA$. Notably, in RRM3, the canonical RRM fold is preceded by an additional $\alpha$-helix located in the RRM2-RRM3 linker (helix $\alpha 0$, Tyr $\left.{ }^{191}-V_{a l}{ }^{196}\right)$, consistent with ${ }^{13} \mathrm{C}$ secondary chemical shifts (Supplementary Figure S2A). Notably, helix $\alpha 0$ packs against RRM3 helix $\alpha 2$ and strand $\beta 4$ and thus defines an enlarged RRM fold for RRM3. Helix $\alpha 0$ is not required for stability of RRM3, as a protein lacking helix 
$\alpha 0$ is stable and folded (Supplementary Figure S1), consistent with a recent report (29). The remaining part of the RRM2-RRM3 linker (Thr ${ }^{172}-$ Ser $^{190}$ ) in RRM2,3 does not form any secondary structure, consistent with random coil secondary chemical shifts and ${ }^{15} \mathrm{~N}$ relaxation data (Supplementary Figure S2A, see also below).

\section{RNA binding of the individual TIA-1 RRM domains}

To characterize the RNA binding properties of the TIA1 RRM domains to pyrimidine-rich ligands, NMR chemical shifts of amides were monitored upon titration of a U9 RNA oligonucleotide to the individual ${ }^{15} \mathrm{~N}$-labeled TIA-1 RRM domains (Figure 4A-C). The stronger chemical shift perturbations (CSPs) (48) of RRM2 upon U9 binding compared to the RRM1 and RRM3 are in agreement with the previously reported higher affinity to uridine-rich RNAs $(12,17,24)$. Notably, in addition to the two RNP motifs, the additional $\mathrm{N}$-terminal helix $\alpha 0$ and $\mathrm{C}$-terminal residues in RRM3 exhibit strong CSPs. This indicates that these regions are affected by binding to the U9 RNA either by engaging direct contacts to the RNA or by indirectly induced conformational changes. The reduced RNA binding of RRM3 reported previously is likely a result of the fact that these studies $(12,17)$ have used a truncated version of RRM3 lacking helix $\alpha 0$.

U9 RNA binding to the individual RRM3 domain is fast on the NMR chemical shift time scale (Figure 4E) as crosspeaks positions are shifting with increasing RNA concentration. Hence, RRM3 binds with a dissociation constant $K_{\mathrm{D}} \sim 30-50 \mu \mathrm{M}$ as derived from the NMR titration (Supplementary information, Figure S3B). Binding kinetics observed with the NMR titrations of RRM2 are fast to intermediate on the NMR chemical shift time scale as some residues disappear and reappear with increasing U9 concentration (e.g. Gly ${ }^{137}$; Figure 4D). When analyzing residues with fast chemical exchange behavior an apparent $K_{\mathrm{D}} \sim 35$ $\mu \mathrm{M}$ is obtained (Supplementary Figure S3A). The binding affinities observed are consistent with ITC measurements for the interaction of mouse TIA-1-RRM2 with a U5 RNA oligonucleotide with $K_{\mathrm{D}} \sim 30 \mu \mathrm{M}$ (28). The observation that RRM2 binding kinetics is fast to intermediate in the NMR titrations indicates a stronger interaction of TIA-1-RRM2 to poly-U RNA compared with RRM3.

Similar chemical shift perturbations are observed for the single RRM2, RRM3 domains and the tandem RRM2,3 protein upon saturated binding to U9 RNA (Figure 4A$\mathrm{E}$, black bars in Figure 4F). This indicates that identical binding interfaces are employed by the isolated RRM domains even though the overall binding affinity of RRM2,3 is much higher due to cooperative effects (see below). Intriguingly, compared with RRM2 and RRM3 (Figure 4B and C), RRM1 exhibits only very minor chemical shift perturbations upon addition of U9 RNA (Figure 4A), which may reflect non-specific contacts due to its overall positively charged surface. To explore whether RRM1 could nevertheless contribute to high affinity RNA-binding in the RRM1,2,3 construct, we performed NMR titrations of RRM1,2,3 with an U15 RNA oligonucleotide. The chemical shift perturbations of RRM1,2,3 upon binding to U15 RNA (Figure 4F; Supplementary Figure S5A) are very sim- ilar for RRM2,3 but very small for RRM1. The CSPs observed for RRM1 within RRM1,2,3 are slightly stronger than seen for the RRM1/U9 RNA interaction but much smaller compared to the CSPs seen for RRM2 and RRM3 and thus do not indicate specific RNA contacts. Thus, RRM1 does not seem to mediate significant contacts with the RNA even in the context of RRM1,2,3. This is further confirmed by ITC data which suggest that RRM1 does not contribute to U15 RNA binding (Supplementary Figure S8 and see below).

Thus, RRM1 lacks significant intrinsic RNA binding activity, consistent with the presence of degenerate RNP motifs (that are normally important for RNA binding, Figure $1 \mathrm{~B}$ ) and might thus primarily be involved in mediating protein-protein interactions. Sequence identities of human TIA-1 compared to those of mouse, frog, zebrafish and human TIAR are 96, 74, 80 and 79\%, respectively (49). A1though the sequence identity is $<35 \%$ between human and Drosophila, the RRM2,3 region shows over $60 \%$ homology, suggesting that the tandem TIA-1-RRM2,3 domains have evolutionary conserved functions in RNA recognition. In contrast, the lower conservation of RRM1 and the Cterminal Q-domain indicate a lower selection pressure for these regions, or that residues involved in RRM1-mediated protein-protein interactions have co-evolved in higher organisms only.

\section{Binding of TIA-1-RRM2,3 to an intronic sequence in FAS pre-mRNA}

Regulation of $F A S$ alternative splicing (Figure 1C) requires binding of TIA-1 to pyrimidine-tracts located in the $5^{\prime}$ region of pre-mRNA introns. To characterize the RNA recognition with a ligand found in a biologically relevant substrate we analyzed the interaction of TIA-1 with 16-mer ( $f a s_{-} 16$ ) and 10-mer RNA ( $f a s_{-} 10$ ) oligonucleotides derived from $F A S$ intron 5 (Figure 1C). This RNA comprises a GU di-nucleotide, resembling an alternative $5^{\prime}$ splice site followed by a strong Py-tract and is located 10-28 nt downstream of the exon/intron boundary of $F A S$ exon 5. A polyuridine oligonucleotide (U9) was used to compare TIA-1 binding to a general pyrimidine-rich ligand.

NMR titration of fas_16, fas_10, and U9 RNA to TIA1-RRM2,3 shows binding in the intermediate to slow exchange regime at the NMR chemical shift time-scale, i.e. NMR signals of residues involved disappear and reappear at a different position upon saturation (Supplementary Figure S6). Therefore, to unambiguously determine the chemical shifts of RRM2,3 bound to fas_16 and fas_10 RNA backbone chemical shifts were re-assigned using triple-resonance experiments. The ${ }^{13} \mathrm{C}$ secondary chemical shifts of the complex show that the secondary structure of RRM2,3 is not altered in the protein-RNA complex (Supplementary Figure S2B). Similar overall CSPs are observed for the amide signals of RRM2,3 upon either fas_16, fas_10 RNA or U9 binding (Figure 5A and B). This seems to reflect that all ligands are pyrimidine-rich and demonstrates that the same binding interface on RRM2,3 is employed for the recognition of these ligands. The binding surface with fas_l $_{-} 16$ is mapped onto a ribbon representation of TIA-1-RRM2,3 (Figure 3B) with significant CSP values (50). The interac- 
(A)
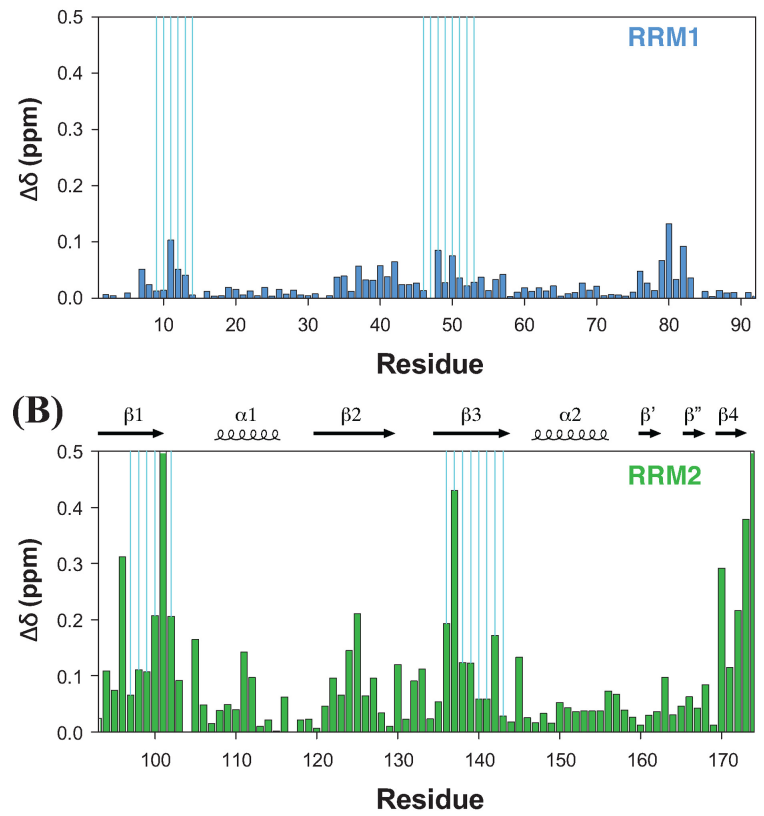

(D) TIA-1-RRM2 vs. U9
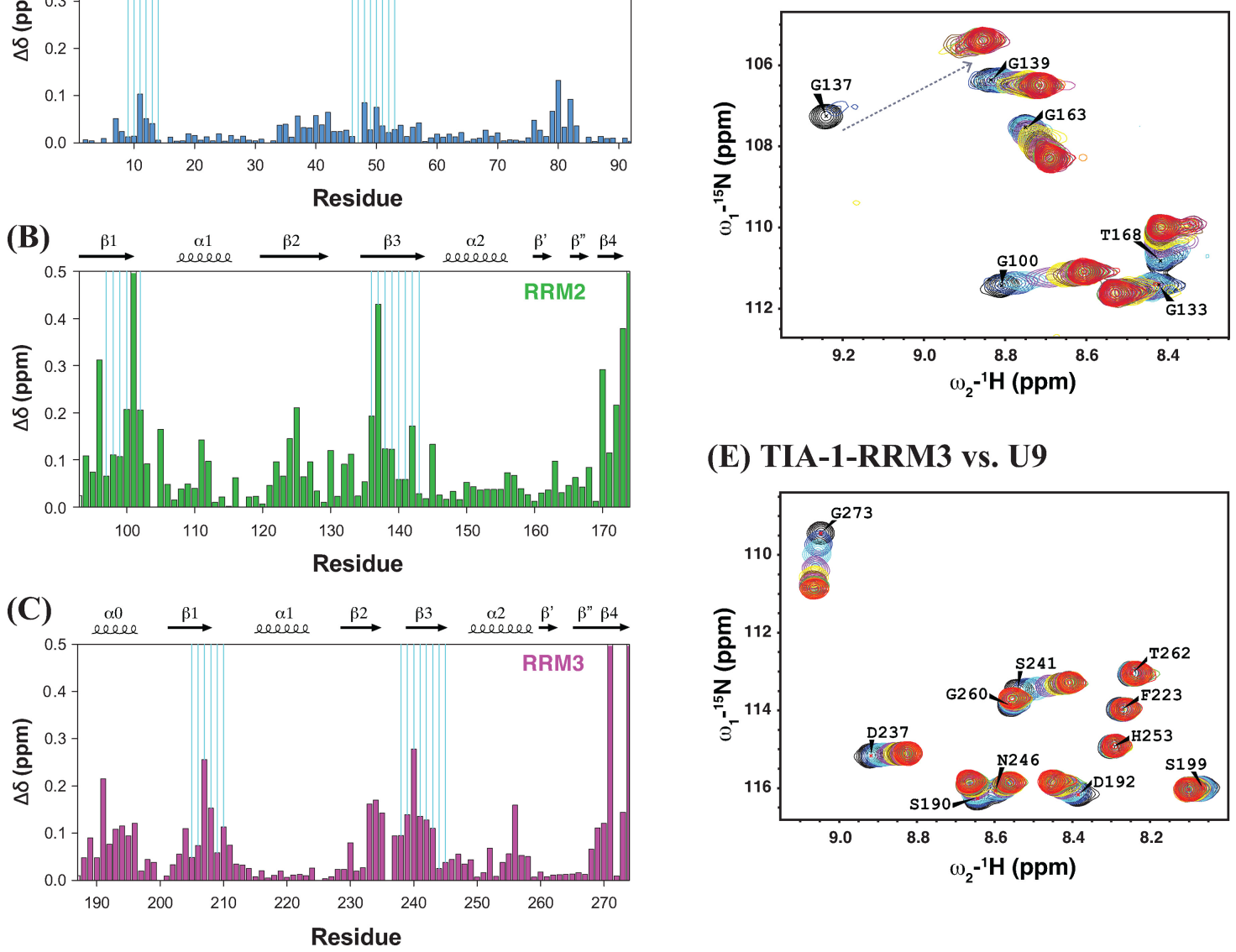

(E) TIA-1-RRM3 vs. U9

(F)

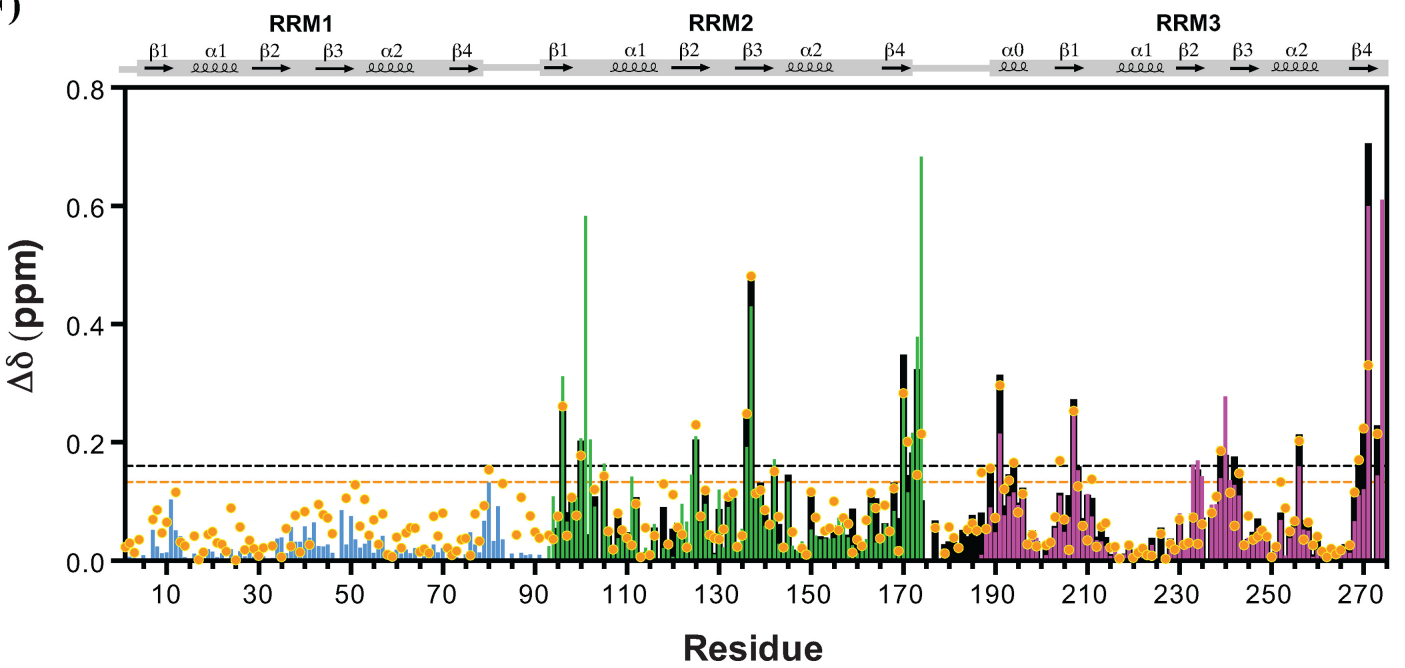

Figure 4. Chemical shift perturbations of individual TIA-1 RRM domains upon binding to U9 RNA. The combined ${ }^{1} \mathrm{H}$ and ${ }^{15} \mathrm{~N}$ chemical shift perturbations were calculated using the equation: $\Delta \delta=\left[\left(\Delta \delta_{\mathrm{HN}}\right)^{2}+\left(\Delta \delta_{\mathrm{N}} / 6.5\right)^{2}\right]^{1 / 2}(48)$. The CSP of amide groups in (A) RRM1, (B) RRM2 and (C) RRM3 are plotted over residues, RNP motifs are indicated by cyan lines. Titration data are shown for zoomed regions of ${ }^{1} \mathrm{H},{ }^{15} \mathrm{~N}$ HSQC spectra of (D) RRM2 and (E) RRM3. Spectra are colored as: free protein (black) and in the presence of U9 RNA RNA at 0.1 (blue), 0.2 (cyan), 0.4 (purple), 0.6 (yellow), 0.8 (brown), 1.0 (magenta), 1.2 (green), 1.4 (gray), 1.6 (orange) and 1.8 (dark-red/red) and 2.0 (red) molar equivalents. (F) Comparison of CSPs of tandem RRM2,3 (black), RRM1 (residues 1-92, in light blue), RRM2 (residues 93-174, in green) and RRM3 (residues 187-274, in magenta) upon binding to U9 RNA with TIA-1-RRM1,2,3 binding to U15 RNA (orange dots). The CSPs are plotted versus residue numbers. The dashed line in black shows a cut-off $\Delta \delta>0.16 \mathrm{ppm}$ (average chemical shift perturbation over all resonances + standard deviation) for RRM2,3 titrated with U9, and the one in orange for $\Delta \delta$ $>0.13$ ppm for RRM1,2,3 with U15. 
(A)

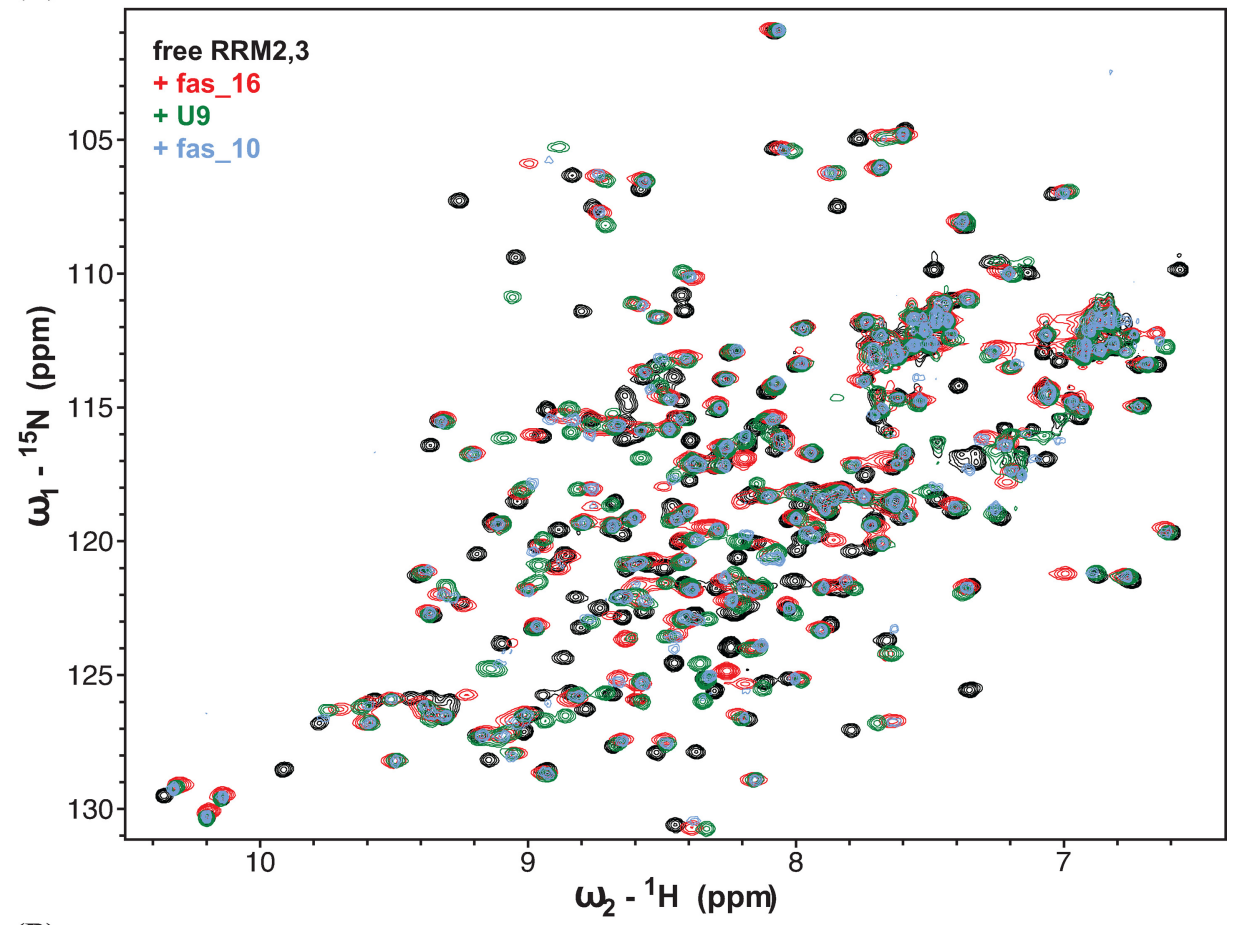

(B)

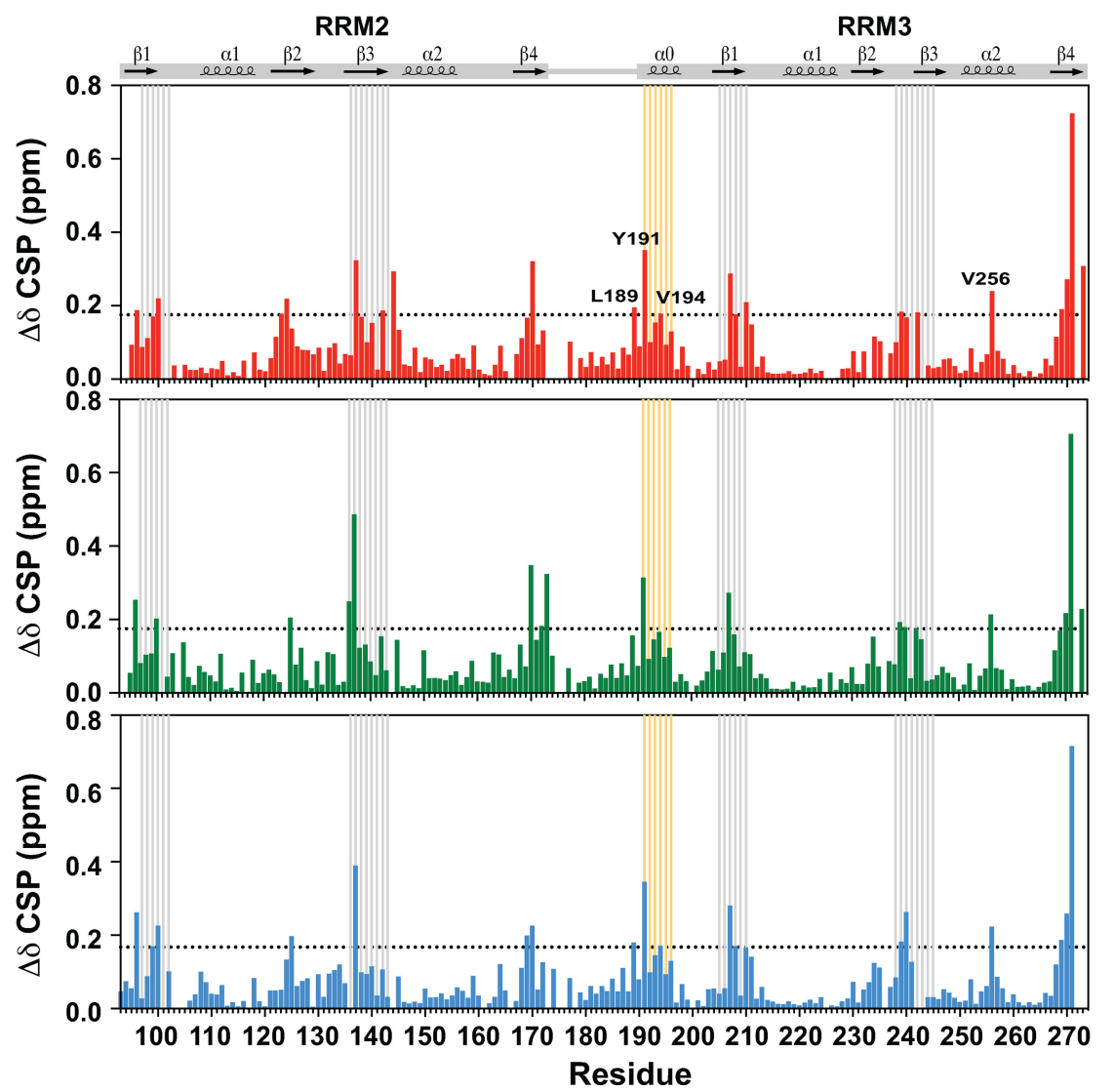

Figure 5. (A) Comparison of ${ }^{1} \mathrm{H},{ }^{15} \mathrm{~N}$ HSQC spectra of free RRM2,3 (black), and bound with fas_16 (red), U9 (green) and fas_10 (light blue) RNA. (B) The combined ${ }^{1} \mathrm{H}$ and ${ }^{15} \mathrm{~N}$ chemical shift perturbations $(\Delta \delta)$ upon saturated binding by fas_l6, U9, and fas_l 10 RNA are shown versus residue number. RNP motifs are indicated with gray lines. Residues of RRM3 helix $\alpha 0$ are highlighted by orange lines, and those with significant CSP are annotated. 
Table 1. Structural statistics for TIA-1 RRM2,3

\begin{tabular}{|c|c|}
\hline Structural statistics for TIA-1-RRM2, $3^{\mathrm{a}}$ & \\
\hline Structure calculation restraints & \\
\hline Distance restraints & \\
\hline Total NOEs & 2104 \\
\hline Intra-residue & 485 \\
\hline Sequential $(|i-j|=1)$ & 581 \\
\hline Medium-range $(|i-j| \leq 4)$ & 395 \\
\hline Long-range $(|i-j|>4)$ & 643 \\
\hline Hydrogen bonds & 154 \\
\hline Dihedral restraints $(\phi+\psi)$ & 272 \\
\hline Quality analysis & \\
\hline Restraints violations (mean $\pm \mathrm{SD}$ ) & \\
\hline Distance restraints $(\AA)$ & $0.016 \pm 0.00$ \\
\hline Dihedral angle restraints $\left(^{\circ}\right)$ & $0.687 \pm 0.06$ \\
\hline Deviation from idealized geometry & \\
\hline Bond length $(\AA)$ & $0.011 \pm 0.00$ \\
\hline Bond angles $\left({ }^{\circ}\right)$ & $1.214 \pm 0.03$ \\
\hline Impropers $\left({ }^{\circ}\right)$ & $1.387 \pm 0.10$ \\
\hline Average pairwise r.m.s. deviation $(\AA)^{\mathrm{a}}$ & \\
\hline Heavy (RRM2/RRM3) & $1.23 \pm 0.15 / 0.88 \pm 0.08$ \\
\hline Backbone (RRM2/RRM3) & $0.64 \pm 0.17 / 0.41 \pm 0.06$ \\
\hline Ramachandran values $(\%)^{\mathrm{a}, \mathrm{b}}$ & \\
\hline Most favored regions & 93.2 \\
\hline Allowed regions & 6.8 \\
\hline Generously allowed regions & 0 \\
\hline Disallowed regions & 0 \\
\hline What If analysis $\mathrm{s}^{\mathrm{a}, \mathrm{c}}$ & \\
\hline First generation packing & $2.590 \pm 0.910$ \\
\hline Second generation packing & $7.285 \pm 2.633$ \\
\hline Ramachandran plot appearance & $-1.157 \pm 0.170$ \\
\hline Chi- $1 /$ Chi-2 rotamer normality & $-1.941 \pm 0.517$ \\
\hline Backbone conformation & $0.408 \pm 0.167$ \\
\hline
\end{tabular}

${ }^{a}$ For residues 93-171 (RRM2) and 191-272 (RRM3)

${ }^{b}$ With Procheck.

${ }^{\mathrm{c}}$ Analyzed by iCING. Structure $Z$-scores, a positive number is better than average.

tion mainly involves the $\beta$-sheet surfaces of RRM2 and RRM3, similar to what has been seen for titrations of U9 RNA to the individual RRMs (Figure 4B and C), and corresponds to the canonical RNA binding surface of RRM domains. Notably, RRM3 helix $\alpha 0$ (Tyr ${ }^{191}$ and $\mathrm{Val}^{194}$ ) as well as residues that are in close spatial proximity (Leu ${ }^{189}$ preceding RRM3 helix $\alpha 0$ and Val ${ }^{256}$ in RRM3 helix $\alpha 2$, Figure $3 \mathrm{~B}$ ) are also strongly affected (Figure 5B).

We used ITC to determine the binding stoichiometry and affinity of TIA-1-RRM2,3 towards U9 and FAS intron RNA (Figure 6; Table 2). Upon titration of TIA-1-RRM2,3 to fas_16 RNA (Figure 1C) two distinct binding sites are observed with $K_{\mathrm{D} 1}=0.35 \mathrm{nM}$ and $K_{\mathrm{D} 2}=27 \mu \mathrm{M}$. In a reverse titration (RNA into protein) an average dissociation constant of $K_{\mathrm{D}}=22 \mu \mathrm{M}$ with $2: 1$ protein:RNA stoichiometry is found (Figure 6A). Upon titration of RRM2,3 into U9 RNA and vice versa dissociation constants of $K_{\mathrm{D}}=7.0$ and $5.6 \mathrm{nM}$ are determined, respectively (Figure 6B). Negative binding enthalpies $\Delta H$ observed for these ligands (Table 2; Supplementary Figure S7) indicate that the RNA binding is enthalpically driven.

Interestingly, the binding stoichiometry of TIA-1RRM2,3 to fas_l6 is $2: 1$ but $1: 1$ for U9. The presence of a high affinity binding site in fas_l6 RNA with $>10$-fold increased binding affinity compared to U9 suggests either the specific recognition of a sequence motif in fas_l6 RNA or avidity effects in binding to a longer pyrimidine-rich stretch, as commonly only $10-12$ nucleotides are recognized by tandem RRMs. Within fas_16 RNA a 10-mer sequence motif may be sufficient for binding to RRM2,3, while the additional nucleotides present in the 16-mer ligand may contribute to avidity by binding in multiple registers and increased local concentrations of the pyrimidine-rich ligand. In an attempt to identify a putative minimal RNA sequence motif within fas_l6 RNA we studied RRM2,3 binding to fas_10, which corresponds to the pyrimidinerich region at the $3^{\prime}$-end of fas_16 (Supplementary Figrue S8A). Upon titration of RRM2,3 into fas_lo RNA, a dissociation constant of $K_{\mathrm{D}} \sim 17 \mathrm{nM}$ was determined with a 1:1 stoichiometry, thus comparable to U9 RNA binding affinity. This suggests that the stronger binding to fas_l6 mainly results from avidity effects upon binding to a longer pyrimidine-rich RNA ligand and that the RNA binding specificity of TIA-1 mainly requires pyrimidine-rich sequence.

In order to compare the contribution of RRM1 in RRM1,2,3 for RNA binding, we carried out ITC titrations of RRM1,2,3 with U15 RNA (Supplementary Figrue S8B). These experiments show $K_{\mathrm{D}}$ values of $16 \mathrm{nM}$ assuming a 1:1 binding event. Thus, the binding affinity of RRM1,2,3 to U15 RNA is similar to that of RRM2,3 to U9. This finding confirms the NMR chemical shift perturbation data which do not suggest strong contributions of RRM1 to 
(A) TIA-1-RRM2,3 vs. fas_16
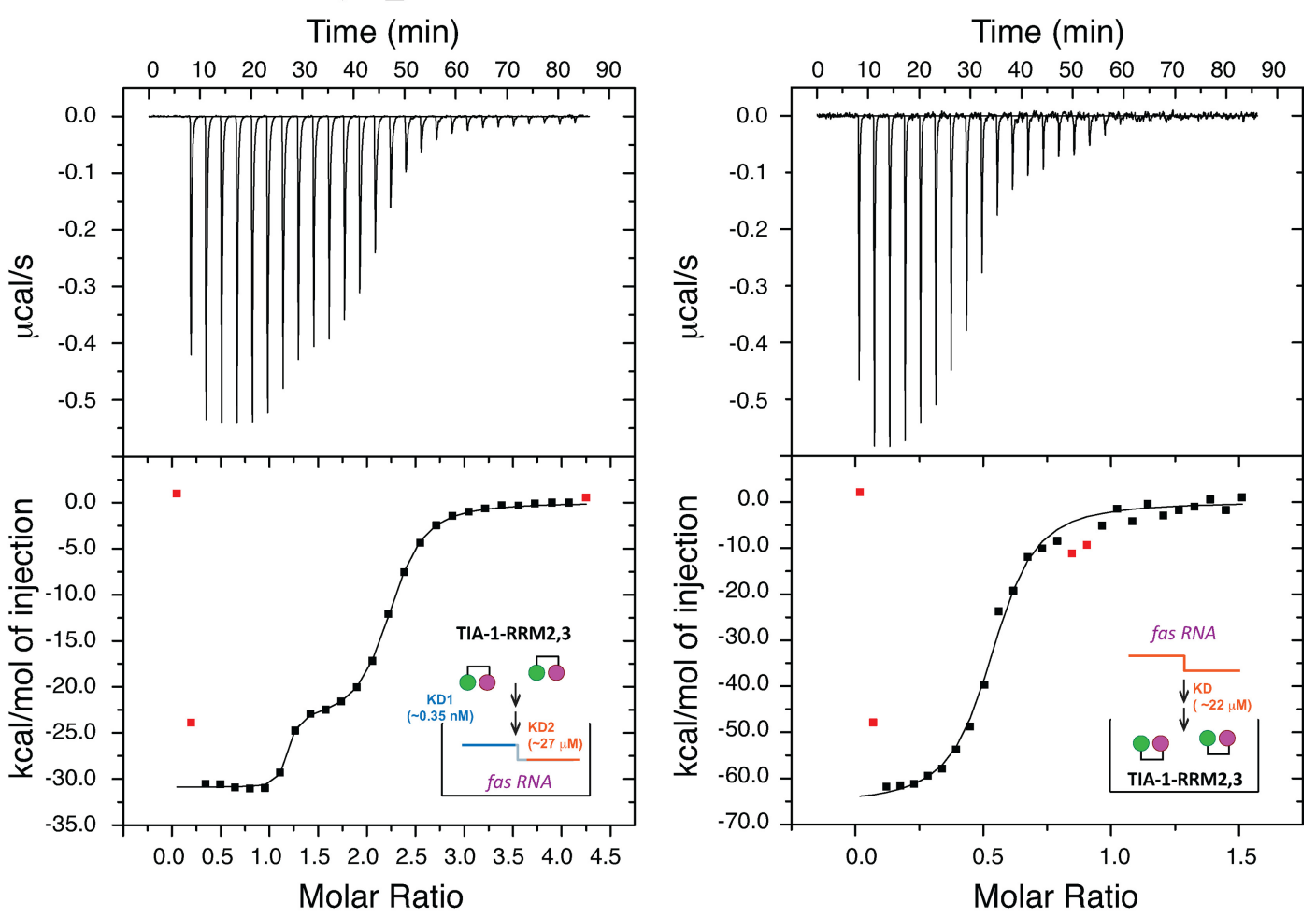

(B) TIA-1-RRM2,3 vs. U9
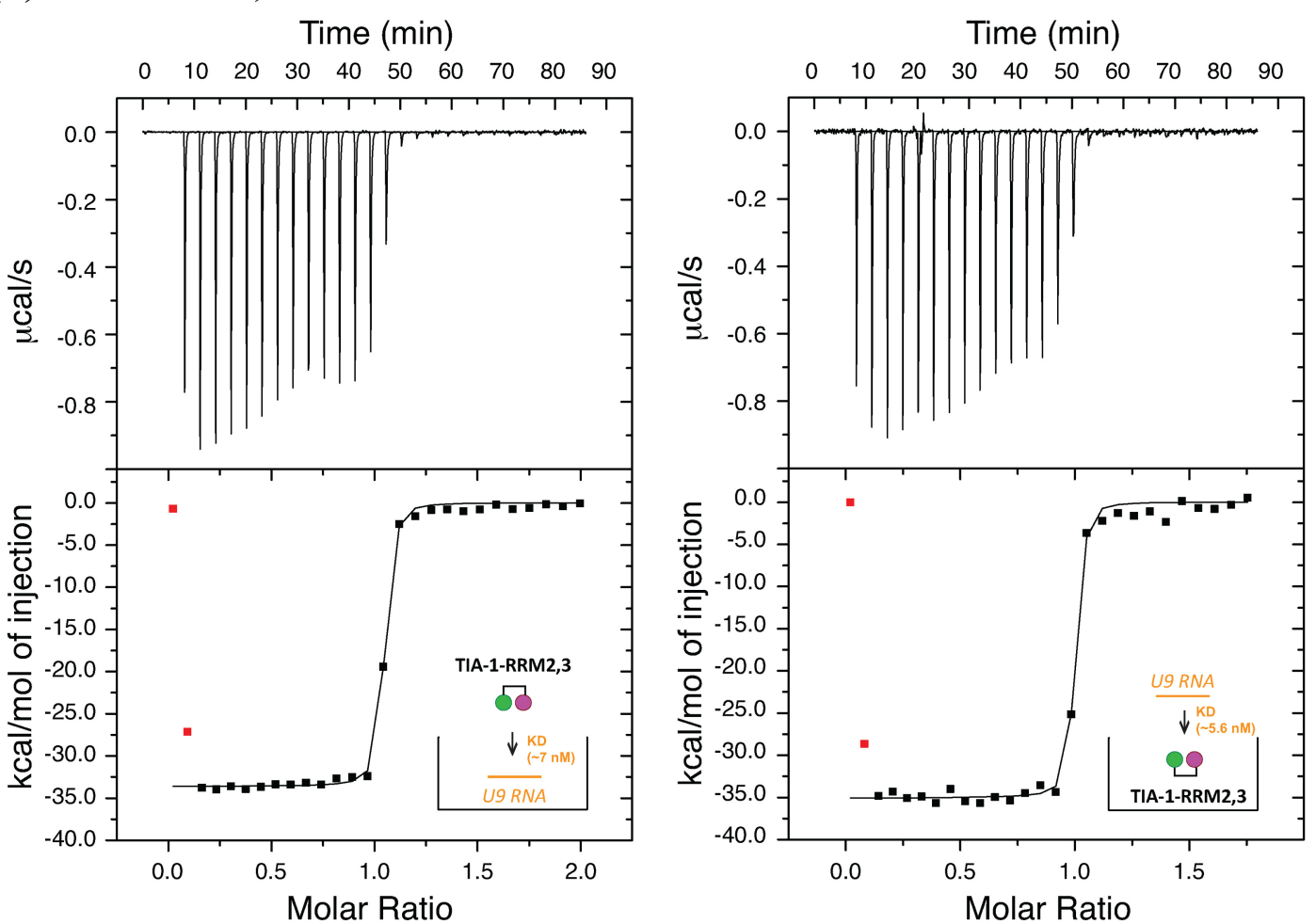

Figure 6. Isothermal titration calorimetry for the binding of TIA-1-RRM2,3 to fas 16 and U9 RNAs. (A) $10 \mu M$ protein (in the calorimetric cell) was titrated with $70 \mu \mathrm{M}$ fas_l6 (in the syringe), and the reverse titration by using TIA-1-RRM2,3 (200 $\mu \mathrm{M}$ ) as titrants into RNA titrate (10 $\mu \mathrm{M})$. (B) $20 \mu \mathrm{M}$ protein was titrated with $200 \mu \mathrm{M}$ U9 RNA, and the reverse titration of protein to U9 with the same concentrations. Each plot shows the heat released versus time in the upper panel with a thermogram of the integrated peak intensities plotted against the molar ratio of the complex in the lower panel. Fitted thermodynamic parameters data for each titration were shown in Table 2. All experiments were conducted in $10 \mathrm{mM}$ sodium phosphate (pH 6.0) with 50 $\mathrm{mM} \mathrm{NaCl}$ at $25^{\circ} \mathrm{C}$ 
Table 2. Isothermal titration calorimetry data for RNA binding of TIA-1 RRM2,3

\begin{tabular}{|c|c|c|c|c|c|c|}
\hline & $K_{\mathrm{A}}\left(\mathrm{M}^{-1}\right)$ & $K_{\mathrm{D}}(\mathrm{nM})$ & $\Delta G(\mathrm{kcal} / \mathrm{mol})$ & $\Delta H(\mathrm{kcal} / \mathrm{mol})$ & $\Delta S(\mathrm{cal} / \mathrm{K} \cdot \mathrm{mol})$ & $N$ \\
\hline \multicolumn{7}{|l|}{ RRM2,3 $\rightarrow$ fas_16 } \\
\hline Site 1 & $(2.9 \pm 1.0) \times 10^{9}$ & $0.4 \pm 0.1$ & $-12.9 \pm 0.2$ & $-30.9 \pm 0.1$ & $-60.4 \pm 0.7$ & 1.1 \\
\hline Site 2 & $(3.7 \pm 0.2) \times 10^{6}$ & $272.5 \pm 14.9$ & $-9.0 \pm 0.0$ & $-23.9 \pm 0.2$ & $-50.1 \pm 0.1$ & 1.1 \\
\hline $\begin{array}{l}\text { fas_16 } \rightarrow \\
\text { RRM2,3 }\end{array}$ & $(4.6 \pm 1.0) \times 10^{6}$ & $216.0 \pm 47.6$ & $-9.1 \pm 0.1$ & $-61.3 \pm 2.1$ & $-175.0 \pm 0.5$ & 0.5 \\
\hline RRM2,3 $\rightarrow$ U9 & $(1.4 \pm 0.3) \times 10^{8}$ & $7.0 \pm 0.2$ & $-11.1 \pm 0.0$ & $-33.6 \pm 0.2$ & $-75.5 \pm 0.1$ & 1.0 \\
\hline U9 $\rightarrow$ RRM2,3 & $(1.8 \pm 0.6) \times 10^{8}$ & $5.6 \pm 1.9$ & $-11.3 \pm 0.2$ & $-35.1 \pm 0.3$ & $-80.0 \pm 0.7$ & 1.0 \\
\hline $\begin{array}{l}\text { RRM2,3 } \rightarrow \\
\text { fas_10 }\end{array}$ & $(2.8 \pm 0.6) \times 10^{7}$ & $35.6 \pm 8.1$ & $-10.2 \pm 0.4$ & $-31.3 \pm 0.3$ & $-71.1 \pm 0.2$ & 1.0 \\
\hline $\begin{array}{l}\text { RRM1,2,3 } \rightarrow \\
\text { U15 }\end{array}$ & $(6.0 \pm 0.9) \times 10^{7}$ & $16.9 \pm 2.7$ & $-10.6 \pm 0.1$ & $-42.4 \pm 0.4$ & $-106.8 \pm 1.1$ & 1.0 \\
\hline
\end{tabular}

The fitting model used: 2-site for RRM2,3 titrated into fas_16, 1-site for all other titrations. The change of Gibbs free energy and entropy were calculated using the equations: $-T \Delta S=\Delta G-\Delta H$ and $\Delta G=-R T \ln \left(K_{\mathrm{A}}\right)$ at $T=298 \mathrm{~K}$.

RNA binding and suggest that RRM2,3 represent the highaffinity RNA binding region of TIA-1.

\section{The TIA-1-RRM2,3-RNA complex is compact}

To study internal motion and characterize the overall domain dynamics we measured ${ }^{15} \mathrm{~N}$ relaxation data for TIA-1 RRM2,3 in the RNA free and bound state (Figure 7A). The average tumbling correlation time for residues in RRM3, $\tau_{\mathrm{c}} \approx 10 \mathrm{~ns}$, resembles the value expected for a molecular weight of $20.4 \mathrm{kDa}$ whereas the average $\tau_{\mathrm{c}}$ of RRM2 of $12 \mathrm{~ns}$ is slightly higher. These values suggest that the rotational diffusion of both domains is coupled, as the correlation times expected for the individual RRM2/RRM $3, \tau_{\mathrm{c}} \approx$ $6.1 \mathrm{~ns} / 5.9 \mathrm{~ns}$, estimated using HYDRONMR (51) are significantly lower than the experimentally derived values in context of the tandem RRM2,3. The presence of motional coupling in multi-domain proteins has been found even in the presence of a relatively long flexible linker connecting two domains (47) to be observed, as is the case for RRM2,3 (Figure 7A). However, the different values determined for the average tumbling correlation times of the two domains suggest that RRM2 and RRM3 do not interact (Figure 7B). The higher values observed for RRM2 (in spite of its smaller molecular weight) presumably reflects non-specific aggregation of this domain, as is also found for the RRM1-RRM2RRM3 fragment (Figure 2C).

Upon binding to fas_l6 RNA both RRMs exhibit the same average tumbling correlation time of $\tau_{\mathrm{c}} \approx 14 \mathrm{~ns}$, a value that is also consistent with the molecular weight of the complex $(25.5 \mathrm{kDa}) .\left\{{ }^{1} \mathrm{H}\right\}-{ }^{15} \mathrm{~N}$ heteronuclear NOE values demonstrate that the RRM2-RRM3 linker (residues 171190) remains highly flexible and does not become ordered upon RNA-binding, consistent with the lack of chemical shift perturbations in the linker region upon RNA binding. Thus, RNA binding by TIA-1 RRM2,3 induces a compact domain arrangement where both domains cooperate in binding to the RNA ligand. We also determined the average tumbling correlation time of RRM1,2,3 bound with U15 ( $\sim 36 \mathrm{kDa})$. Although $\tau_{\mathrm{c}}$ values for RRM2 ( 18 ns) are still slightly larger than for RRM1 $(\sim 16 \mathrm{~ns})$ or RRM3 $(\sim 16.5 \mathrm{~ns})$ (Supplementary Figrue S5B), the overall similar values suggests that in the RRM1,2,3/U15 RNA complex the three RRMs tumble together.
To provide additional support for the formation of a compact protein-RNA complex we recorded SAXS data for free and fas_l6 RNA bound TIA-1 RRM2,3 (Figure 7C). Upon RNA binding the radius of gyration, $R_{\mathrm{g}}$, decreases from $24.1 \pm 0.1$ to $22.0 \pm 0.26 \AA$ based on the Guinier approximation or $24.4 \pm 0.003$ to $21.6 \pm 0.003 \AA$ as calculated from the pairwise distribution function (Figure 7D). The maximum pairwise distance, $D_{\max }$, decreases from $80 \AA$ in the absence of RNA to $67 \AA$ upon RNA binding (SAXS statistics according to Jacques et al. (41) are listed in Supplementary Table S1). The larger $R_{\mathrm{g}}$ for TIA-1 RRM2,3 in the absence of RNA confirms that the two RRMs have no fixed orientation towards each other. The averaged ensemble is therefore larger in diameter than in the presence of RNA, where the $R_{\mathrm{g}}$ decreases substantially.

\section{DISCUSSION}

Here, we have identified RRM2 and RRM3 as the bona fide RNA binding domains of TIA-1 and report the highresolution structures of RRM2 and RRM3 within a protein comprising the tandem TIA-1 RRM2,3. In the absence of RNA, the three RRMs of TIA-1 tumble independently as shown by NMR relaxation data and the lack of observable inter-domain NOEs in RRM2,3. The same is true for RRM2 and RRM3 within the TIA-1 RRM2,3 tandem domain construct, where NMR relaxation data indicate that the two domains tumble independently. However, we cannot exclude that weak and transient contacts between RRM2 and RRM3 may exist as has been suggested in a recent study where the presence of RRM2 was found to thermodynamically stabilize RRM3 in thermal unfolding experiments (29). In any case, our NMR data clearly indicate that both domains cooperate in binding to RNA ligands. When bound to RNA, both RRM domains exhibit a uniform tumbling rate, suggesting a synergistic effect in RNA binding by TIA-1-RRM2,3 and the formation of a compact protein-RNA complex. This is corroborated by SAXS measurements, where the gyration radius of RNA bound RRM2,3 is decreased by $12 \%$ compared with free RRM2,3.

We found that RRM3 represents a novel extended RRM structure where the canonical RRM fold is preceded by an $\mathrm{N}$-terminal helix $\alpha 0$. The presence of an N-terminal he- 
(A)
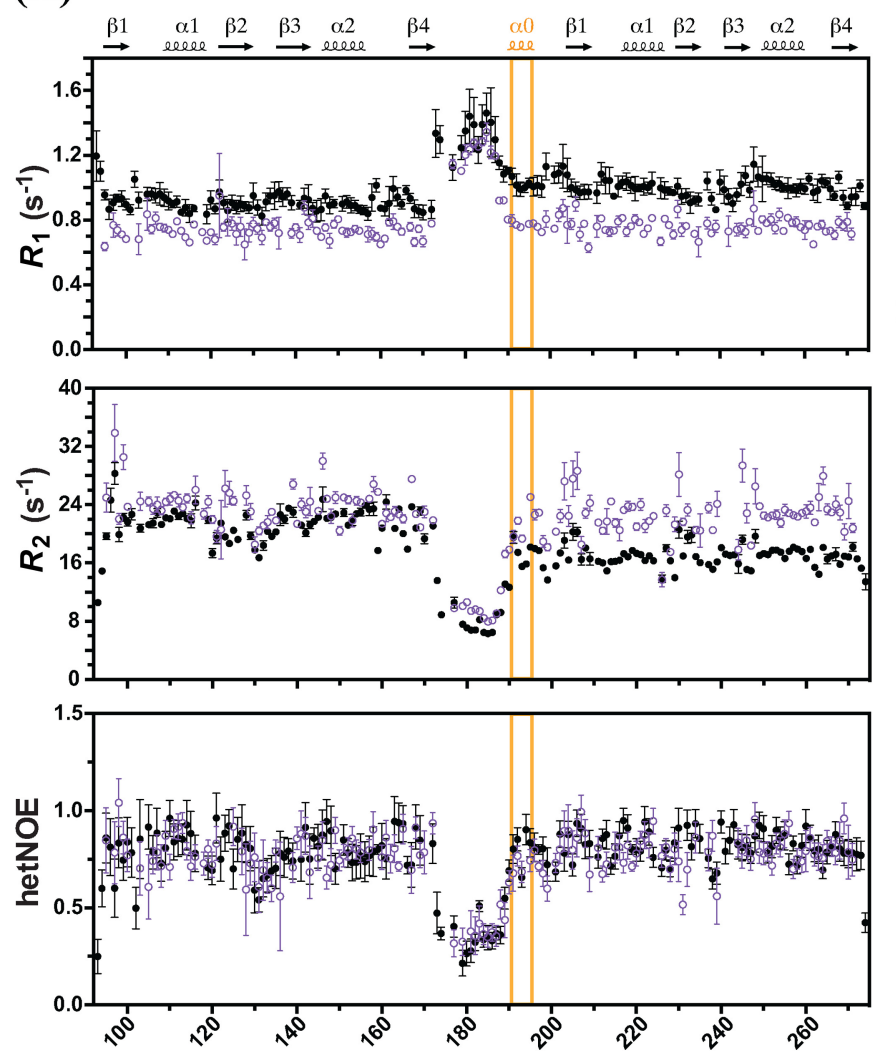

(B)
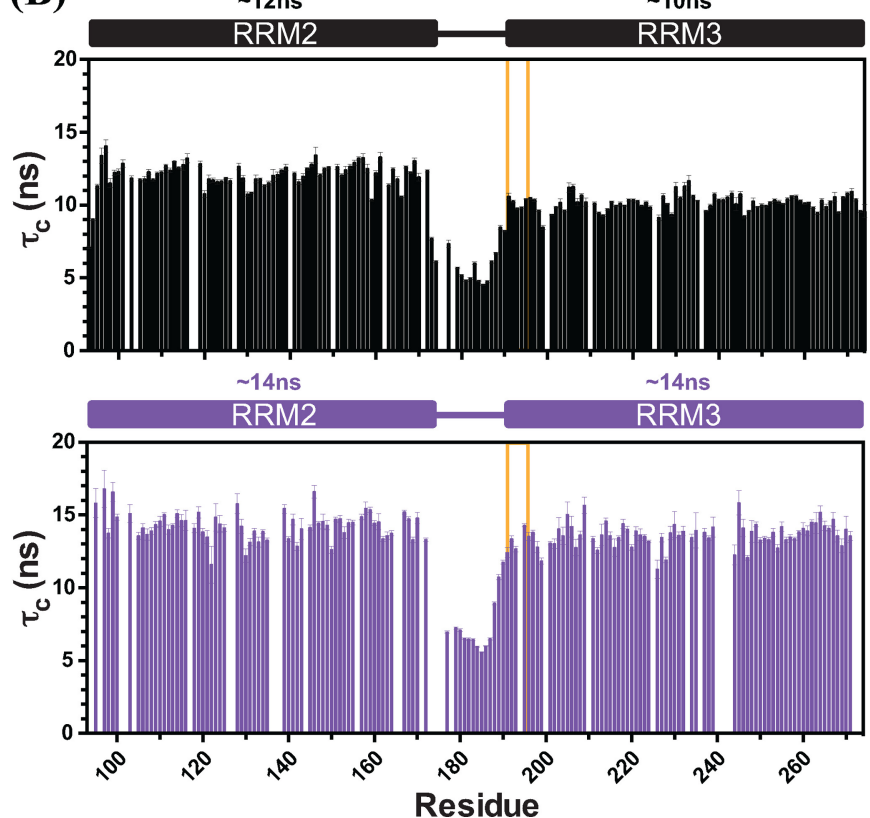

(C)

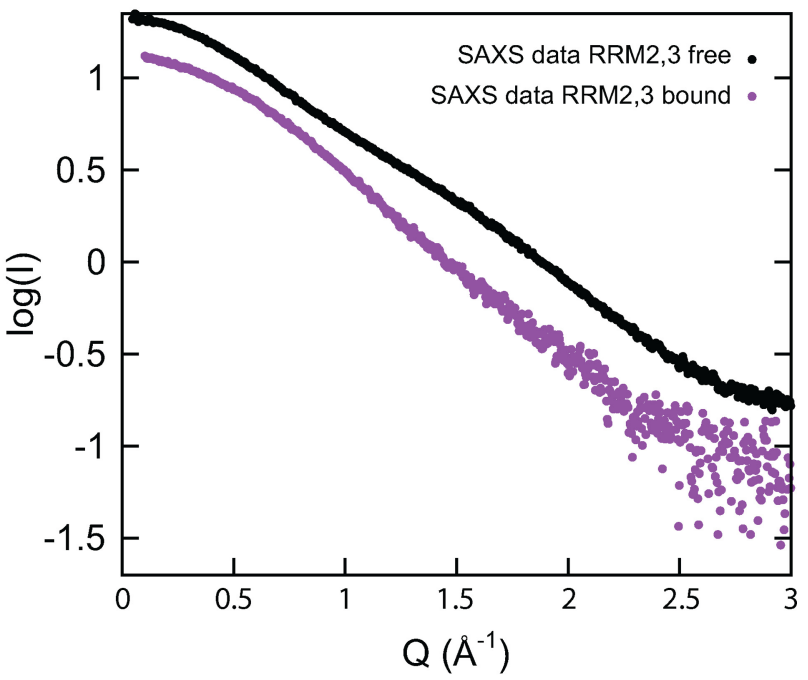

(D)

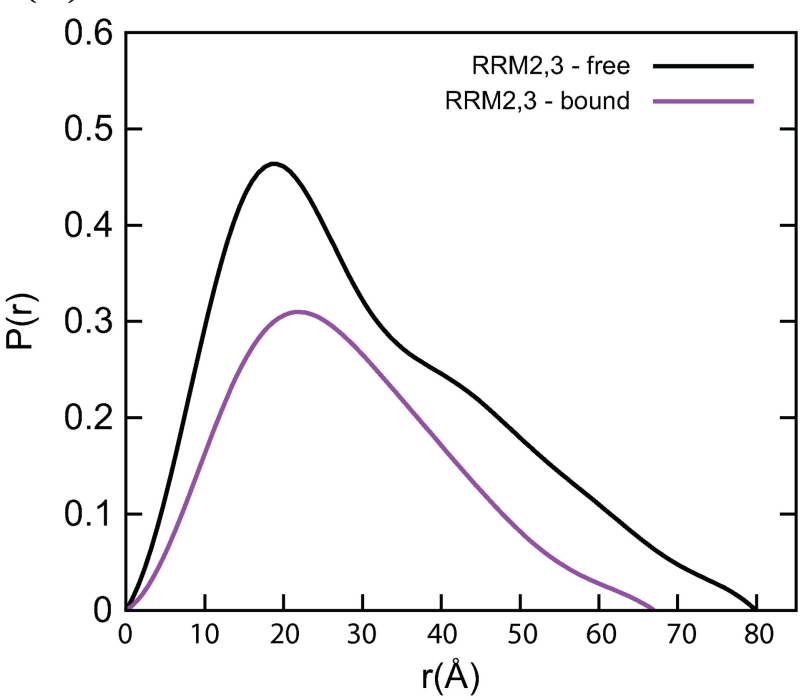

Figure 7. Relaxation and SAXS data of free and fas_l6 RNA bound TIA-1-RRM2,3. (A) $R_{1}$ (top), $R_{2}$ (derived from $R_{p_{0}}$, middle) and $\left\{{ }^{1} \mathrm{H}\right\}-{ }^{15} \mathrm{~N}$ heteronuclear NOE values (bottom) of free (closed circles in black) and bound form (open circles in purple) measured at $298 \mathrm{~K}$ and $\mathrm{pH} 6.0$ are shown. The average rotational correlation times $\left(\tau_{c}\right)$ for RRM2 and RRM3 in the RRM2,3 protein free (black) and bound to fas_l6 (purple) are compared in (B). Residues in RRM3 helix $\alpha 0$ are highlighted with an orange box. (C) SAXS data of TIA-1-RRM2,3 free (black) and bound to fas_l6 RNA (purple) and (D) the corresponding pairwise distribution functions. 
lix has been proposed recently (29) and is also observed in the RRM3 of TIAR (PDB: 1X4G), indicating that this is a conserved feature of TIA proteins (Figure 8A and B). It has been previously speculated that this helix does not contribute additional RNA contacts (25). However, our data clearly indicate that RRM3 helix $\alpha 0$ plays a critical role in RNA recognitions, as residues in this helix experience almost the strongest chemical shift perturbations upon RNA binding. Interestingly, the strong chemical shift perturbations for RRM3 helix $\alpha 0$ upon RNA binding have not been observed in a recent study with the isolated RRM3 domain (25). Although in this study an AU-rich RNA ligand was used, this suggests that TIA-1 RNA binding depends on cooperative interactions involving both RRM2 and RRM3. Notably, His 248 in helix $\alpha 0$ and additional histidine residues located within or near the RNA binding surface may play a role for the suggested $\mathrm{pH}$-dependence of RNA binding by TIA-1 RRM3, even though these effects have not been confirmed in larger constructs of TIA-1 (25). Other structural extensions and variations of the canonical RRM fold have been reported recently (52-53). Comparison of TIA-1-RRM3 with other non-canonical RRM domains indicates that their helical extensions can also mediate additional RNA contacts, as for example seen in the Cst64 RRM (Figure 8C) (54). In contrast the C-terminal RRM domain of the human La protein shields the $\beta$-sheet surface and thus blocks RNA binding (Figure 8D) (55).

It seems plausible that helix $\alpha 0$ in TIA-1-RRM3 directly enhances RNA binding and thus provides additional contacts for RNA recognition. Residues in helix $\alpha 0$ (YDEVV) could mediate such additional contacts. Figure 3B (box) shows that the side chains of $\mathrm{Val}^{194}$ and $\mathrm{Leu}^{189}$ pack against helix $\alpha 2$ in RRM3, while Asp ${ }^{192}$ and Glu ${ }^{193}$ are solvent exposed. However, Tyr $^{191}$ is partially exposed and may thus mediate additional contacts with the RNA ligands, thereby contributing to RNA binding. Taken together our data indicate that the tandem RRM2,3 domain of TIA-1 represents two canonical $\beta$-sheet surfaces for RNA binding that are extended by the novel helix $\alpha 0$. High-resolution structural analysis of the RRM2,3/RNA complex will be required to unravel how both RRM domains cooperate in RNA recognition and how helix $\alpha 0$ enhances these interactions.

The NMR titrations of the three individual RRMs of TIA-1 with U9 RNA confirm previous reports that RRM1 does not bind RNA and that RRM2 and RRM3 mediate the specific RNA binding by TIA-1 $(12,17)$. ITC measurements indicate the presence of two binding sites in fas_16 RNA for TIA-1-RRM2,3. The higher affinity site $\left(K_{\mathrm{D}}=\right.$ $0.35 \mathrm{nM})$ is 20 -fold stronger than $\mathrm{U} 9\left(K_{\mathrm{D}}=7 \mathrm{nM}\right)$. However, the higher affinity is most likely due to avidity effects as RRM2,3 has comparable binding affinity to a shorter RNA derived from fas_16 (fas_10, 5'-UUCUCCUUUC-3') or U9 RNA. This suggests, that TIA-1 does not discriminate between different poly-pyrimidine stretches and that binding affinity can be significantly increased by avidity effects, as seen with other protein-ligand interactions $(24,56)$ and consistent with the presence of longer $(>10 \mathrm{nt})$ pyrimidine-rich sequences in the RNA targets of TIA-1.

A number of non-canonical RRM domains with degenerate RNP1 and RNP2 motifs have been found to mediate protein-protein interactions rather than RNA recognitions.
These non-canonical RRMs, also called U2AF-homology motifs (UHMs) (57), can bind to protein partners through a tryptophan-containing peptide motif (UHM-ligand motifs, ULM) (58-61) and often play roles in the regulation of alternative splicing (60-61). The distinct characteristics of UHMs compared to canonical RRM domains encompass atypical RNP-like motifs, an RXY/F motif in the last loop, and an acidic extension of the first helix. Notably, some of these features are observed for TIA-1 RRM1, i.e. the first RNP1 residue is aspartic acid instead of lysine residue in both RRM2 and RRM3 (Figure 1B). RRM1 harbors an $\mathrm{RXI} / \mathrm{L} / \mathrm{V}$ motif in a $\mathrm{C}$-terminal loop that resembles the characteristic RXY/F motif of UHM domains. Although TIA-1-RRM1 is overall positively charged our NMR titrations with poly-uridine-RNA demonstrates that RRM1 only weakly interacts with RNA and mediates primarily non-specific interactions. Indeed, the binding of RRM1,2,3 to U15 RNA shows comparable affinities than RRM2,3 to U9 RNA, suggesting that RRM1 is dispensable for high affinity RNA binding. It is thus likely that a main function of RRM1 is to mediate protein-protein rather than RNA interactions. Consistent with this notion is the recent observation that RRM1 is dispensable for binding to an AU-rich RNA ligand (24). Some minor contribution to binding of poly-U RNA reported by the same authors may indeed reflect non-specific RRM1 interactions, consistent with our NMR titrations. A recent study by Kielkopf $e t$ al. concluded that RRM1 contributes to high affinity RNA binding to poly-uridine RNA (U20) but not to FAS RNA. In this study mutations of the RNP motifs in RRM1 decreased the affinity to U20 RNA (621). It is possible that the elimination of weak contacts of RRM1 with the RNA influences local concentration or avidity effects. This could also explain why the same authors did not observe a contribution of RRM1 in binding to a 31 nt FAS RNA ligand, which contains pyrimidine-stretches interspersed with purine bases and thus may not support avidity effects.

In recent years, it has been shown that domain arrangements and dynamics play an important role for molecular function and ligand binding of multi-domain proteins. A1though many RRM-RNA complex structures have been reported, most involve individual RNA-binding domains bound to single-stranded RNAs (56,62-64. While these structures reveal details of the RNA recognition for individual domains, the role of multi-domain arrangements and dynamics is not analyzed. Weak domain interactions and dynamics can play important roles for ligand binding and the arrangements of multiple domains in solution might be different than observed by crystallographic studies $(56,65)$. As TIA-1-RRM2 possesses the dominant RNA binding ability of TIA-1, RNA binding by RRM2,3 may utilize initial contacts by RRM2 to a specific RNA motif, while RRM3, connected with a 20-residue flexible linker might search for additional RNA motifs using a fly casting mechanism (Figure 8E).

Compared to other alternative splicing factors that bind close to either $3^{\prime}$ or $5^{\prime}$ splice sites (66-67), TIA-1 binding was only found downstream of exons to recruit U1 snRNP to the $5^{\prime}$ splice sites (12-13). For example, RNA binding of TIA-1 requires U1 snRNP to form a cooperative complex at a specific location in the pre-mRNA. Recent iCLIP 
(A)

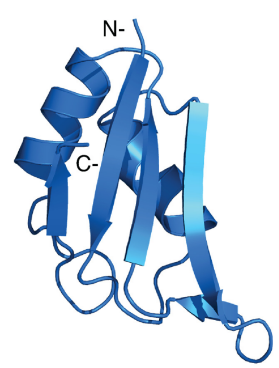

TIA-1-RRM2
(B)

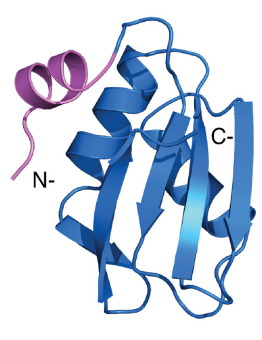

TIA-1-RRM3
(C)

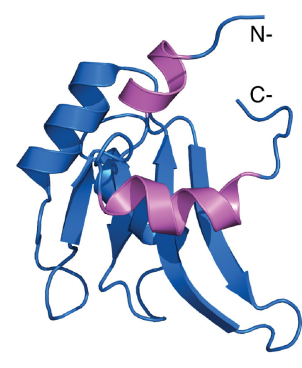

Cst64 RRM
(D)

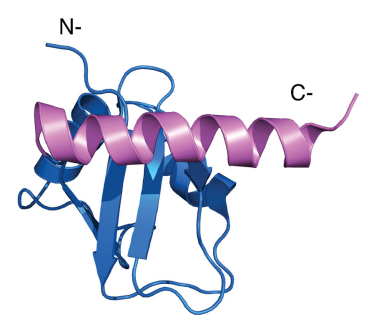

La-C-RRM

(E)

(l)

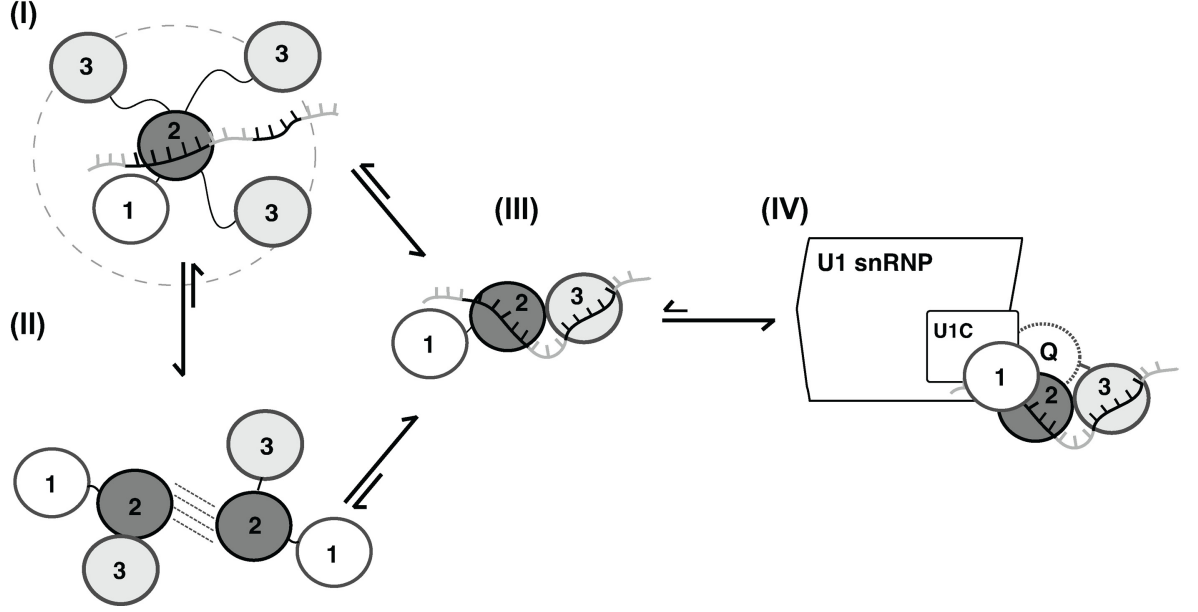

Figure 8. Comparison of the RRM domains of (A) TIA-1 RRM2, (B) TIA-1 RRM3, (C) Cst64 RRM (1P1T) (54) and (D) La-C-RRM (1OWX) (55). Nor C-terminal helical extensions are colored in magenta. (E) A model for RNA and protein interactions by TIA-1 RRM2,3. In free RRM1,2,3 individual RRM domains tumble independently. RRM2 mediates initial contacts to an RNA ligand followed by fly-casting of RRM3 for formation of a stable and rigid RRM2,3-RNA complex (I). Although there are no strong and specific domain-domain contacts detected in free RRM2,3, transient/pre-existing domain-domain interactions between RRM2 and RRM3 may contribute to speed up RNA recognition and skipping the fly casting step as shown in (II). The RRM1 and Q-domains mainly contribute to U1 snRNP recruitment by mediating protein-protein interactions.

data show that TIA-1 binds equally well to Py-tracts downstream of constitutive and alternative exons and its binding downstream of constitutive exons promotes efficient splicing of the corresponding intron, suggesting an importance of distal regulatory sites for the regulation of alternative splicing (26). Thus, more data are required to gain more details for how TIA-1 manages its recognition with various RNAs, especially with different RNA ligands downstream to the constitutive and alternative exons. Besides of binding to similar U-rich stretches, TIA-1 and TIAR recognize cytosine/uridine-rich (C-rich) elements according to SELEX analysis and gene array studies $(4,68)$. Therefore, the higher affinity RNA binding site $\left(K_{\mathrm{D} 1} \sim 0.35 \mathrm{nM}\right)$ in FAS intron 5 ( fas_l $_{-}$) seen in our ITC analysis may represent such a cytosine and uridine-rich site and thus explain the specificity over poly-uridine RNA (U9). Future studies and structural analysis of protein-RNA complexes will help to unravel the sequence specificity of RNA recognition by TIA-1 and the molecular basis for the cooperative binding of TIA-1 and U1 snRNP to the pre-mRNA.

\section{STRUCTURE COORDINATES AND NMR DATA}

Atomic coordinates of TIA-1-RRM2,3 have been deposited in the RCSB Protein Data Bank with accession number 2MJN, while NMR chemical shift data and restraint files are available at the BMRB (accession number: 19735).

\section{ACCESSION NUMBERS}

PDB: 2RNE, 3BS9 and 1X4G.

\section{SUPPLEMENTARY DATA}

Supplementary Data are available at NAR Online, including $[1,2]$.

\section{ACKNOWLEDGMENTS}

We thank Fatiha Kateb for help with NMR relaxation measurements and discussions, the ESRF for beamtime on BM29 and local contact Dr Louiza Zerrad for support and the Bavarian NMR Centre for NMR measurement time. We 
are grateful Clara Kielkopf for providing bacterial expression vectors for TIA-1.

\section{FUNDING}

Fellowship from the Postdoctoral Research Abroad Program sponsored by the National Science Council (NSC) of the R.O.C. (Taiwan) [to I.W.] ; fellowships from the Swedish Research Council (Vetenskapsrådet) and the European Molecular Biology Organization [EMBO, ALTF 276-2010 to J.H.]; Boehringer-Ingelheim funds for a Ph.D. fellowship [to P.K.A.J.]; Deutsche Forschungsgemeinschaft [SFB1035, GRK1721 to M.S.].

Conflict of interest statement. None declared.

\section{REFERENCES}

1. Forch,P., Puig,O., Kedersha,N., Martinez,C., Granneman,S., Seraphin,B., Anderson,P. and Valcarcel,J. (2000) The apoptosis-promoting factor TIA-1 is a regulator of alternative pre-mRNA splicing. Mol. Cell, 6, 1089-1098.

2. Zuccato,E., Buratti,E., Stuani,C., Baralle,F.E. and Pagani,F. (2004) An intronic polypyrimidine-rich element downstream of the donor site modulates cystic fibrosis transmembrane conductance regulator exon 9 alternative splicing. J. Biol. Chem., 279, 16980-16988.

3. Singh,N.N., Seo,J., Ottesen,E.W., Shishimorova,M., Bhattacharya,D. and Singh,R.N. (2011) TIA1 prevents skipping of a critical exon associated with spinal muscular atrophy. Mol. Cell. Biol., 31, 935-954.

4. Lopez de Silanes,I., Galban,S., Martindale,J.L., Yang,X., Mazan-Mamczarz,K., Indig,F.E., Falco,G., Zhan,M. and Gorospe,M. (2005) Identification and functional outcome of mRNAs associated with RNA-binding protein TIA-1. Mol. Cell. Biol., 25, 9520-9531.

5. Kawai,T., Lal,A., Yang,X., Galban,S., Mazan-Mamczarz,K. and Gorospe,M. (2006) Translational control of cytochrome c by RNA-binding proteins TIA-1 and HuR. Mol. Cell. Biol., 26, 3295-3307.

6. Piecyk,M., Wax,S., Beck,A.R., Kedersha,N., Gupta,M., Maritim,B. Chen,S., Gueydan,C., Kruys,V., Streuli,M. et al. (2000) TIA-1 is a translational silencer that selectively regulates the expression of TNF-alpha. EMBO J., 19, 4154-4163.

7. Damgaard,C.K. and Lykke-Andersen,J. (2011) Translational coregulation of 5'TOP mRNAs by TIA-1 and TIAR. Genes Dev., 25, 2057-2068.

8. Ivanov,P., Kedersha,N. and Anderson,P. (2011) Stress puts TIA on TOP. Genes Dev., 25, 2119-2124.

9. Tian,Q., Taupin,J., Elledge,S., Robertson,M. and Anderson,P. (1995) Fas-activated serine/threonine kinase (FAST) phosphorylates TIA-1 during Fas-mediated apoptosis. J. Exp. Med., 182, 865-874.

10. Izquierdo,J.M., Majos,N., Bonnal,S., Martinez,C., Castelo,R., Guigo,R., Bilbao,D. and Valcarcel,J. (2005) Regulation of Fas alternative splicing by antagonistic effects of TIA-1 and PTB on exon definition. Mol. Cell, 19, 475-484.

11. Cheng,J., Zhou,T., Liu,C., Shapiro,J.P., Brauer,M.J., Kiefer,M.C., Barr,P.J. and Mountz,J.D. (1994) Protection from Fas-mediated apoptosis by a soluble form of the Fas molecule. Science, $\mathbf{2 6 3}$ 1759-1762.

12. Forch,P., Puig,O., Martinez,C., Seraphin,B. and Valcarcel,J. (2002) The splicing regulator TIA-1 interacts with U1-C to promote U1 snRNP recruitment to 5' splice sites. EMBO J., 21, 6882-6892.

13. Gesnel,M.C., Theoleyre,S., Del Gatto-Konczak,F. and Breathnach,R. (2007) Cooperative binding of TIA-1 and U1 snRNP in K-SAM exon splicing activation. Biochem. Biophys. Res. Commun., 358, 1065-1070.

14. Del Gatto-Konczak,F., Bourgeois,C.F., Le Guiner,C., Kister,L., Gesnel,M.C., Stevenin,J. and Breathnach,R. (2000) The RNA-binding protein TIA-1 is a novel mammalian splicing regulator acting through intron sequences adjacent to a 5 ' splice site. Mol. Cell. Biol., 20, 6287-6299.
15. Aznarez,I., Barash,Y., Shai,O., He,D., Zielenski,J., Tsui,L.C., Parkinson,J., Frey,B.J., Rommens,J.M. and Blencowe,B.J. (2008) A systematic analysis of intronic sequences downstream of $5^{\prime}$ splice sites reveals a widespread role for U-rich motifs and TIA1/TIAL1 proteins in alternative splicing regulation. Genome Res., 18 1247-1258.

16. Izquierdo,J.M. and Valcarcel,J. (2007) Fas-activated serine/threonine kinase (FAST K) synergizes with TIA-1/TIAR proteins to regulate Fas alternative splicing. J. Biol. Chem., 282, 1539-1543.

17. Dember,L.M., Kim,N.D., Liu,K.Q. and Anderson,P. (1996) Individual RNA recognition motifs of TIA-1 and TIAR have different RNA binding specificities. J. Biol. Chem., 271, 2783-2788.

18. Forch,P. and Valcarcel,J. (2001) Molecular mechanisms of gene expression regulation by the apoptosis-promoting protein TIA-1. Apoptosis, 6, 463-468.

19. Izquierdo,J.M. and Valcarcel,J. (2007) Two isoforms of the T-cell intracellular antigen 1 (TIA-1) splicing factor display distinct splicing regulation activities. Control of TIA-1 isoform ratio by TIA-1-related protein. J. Biol. Chem., 282, 19410-19417.

20. Reyes, R., Alcalde,J. and Izquierdo,J.M. (2009) Depletion of T-cell intracellular antigen proteins promotes cell proliferation. Genome Biol., 10, R87.

21. Larkin,M.A., Blackshields,G., Brown,N.P., Chenna,R., McGettigan,P.A., McWilliam,H., Valentin,F., Wallace,I.M., Wilm,A., Lopez, R. et al. (2007) Clustal W and Clustal X version 2.0. Bioinformatics, 23, 2947-2948.

22. Gouet,P., Courcelle,E., Stuart,D.I. and Metoz,F. (1999) ESPript: analysis of multiple sequence alignments in PostScript. Bioinformatics, 15, 305-308.

23. Gouet,P., Robert,X. and Courcelle,E. (2003) ESPript/ENDscript: extracting and rendering sequence and $3 \mathrm{D}$ information from atomic structures of proteins. Nucleic Acids Res., 31, 3320-3323.

24. Bauer,W.J., Heath,J., Jenkins,J.L. and Kielkopf,C.L. (2011) Three RNA recognition motifs participate in RNA recognition and structural organization by the pro-apoptotic factor TIA-1. J. Mol. Biol., 45, 727-740.

25. Cruz-Gallardo,I., Aroca,A., Persson,C., Karlsson,B.G. and Diaz-Moreno,I. (2013) RNA binding of T-cell intracellular antigen-1 (TIA-1) C-terminal RNA recognition motif is modified by $\mathrm{pH}$ conditions. J. Biol. Chem., 288, 25986-25994.

26. Wang,Z., Kayikci,M., Briese,M., Zarnack,K., Luscombe,N.M., Rot,G., Zupan,B., Curk, T. and Ule,J. (2010) iCLIP predicts the dual splicing effects of TIA-RNA interactions. PLoS Biol., 8, e1000530.

27. Kumar,A.O., Swenson,M.C., Benning,M.M. and Kielkopf,C.L. (2008) Structure of the central RNA recognition motif of human TIA-1 at 1.95A resolution. Biochem. Biophys. Res. Commun., 367, 813-819.

28. Kuwasako,K., Takahashi,M., Tochio,N., Abe,C., Tsuda,K., Inoue,M., Terada,T., Shirouzu,M., Kobayashi,N., Kigawa,T. et al. (2008) Solution structure of the second RNA recognition motif (RRM) domain of murine T cell intracellular antigen-1 (TIA-1) and its RNA recognition mode. Biochemistry, 47, 6437-6450.

29. Aroca,A., Diaz-Quintana,A. and Diaz-Moreno,I. (2011) A structural insight into the C-terminal RNA recognition motifs of T-cell intracellular antigen-1 protein. FEBS Lett., 585, 2958-2964.

30. Delaglio,F., Grzesiek,S., Vuister,G.W., Zhu,G., Pfeifer,J. and Bax,A. (1995) NMRPipe: a multidimensional spectral processing system based on UNIX pipes. J. Biomol. NMR, 6, 277-293.

31. Goddard,T.D. and Kneller,D.G. SPARKY 3.

32. Johnson,B.A. and Blevins,R.A. (1994) NMR view: a computer program for the visualization and analysis of NMR data. J. Biomol. $N M R, 4,603-614$

33. Sattler,M., Schleucher,J. and Griesinger,C. (1999) Heteronuclear multidimensional NMR experiments for the structure determination of proteins in solution employing pulsed field gradients. Prog. Nucl. Magn. Reson. Spectrosc., 34, 93-158.

34. Grzesiek,S. and Bax,A. (1993) Amino acid type determination in the sequential assignment procedure of uniformly $13 \mathrm{C} / 15 \mathrm{~N}$-enriched proteins. J. Biomol. NMR, 3, 185-204.

35. Yamazaki,T., Forman-Kay,J.D. and Kay,L.E. (1993) Two-dimensional NMR experiments for correlating carbon-13.beta. and proton.delta./.epsilon. chemical shifts of aromatic residues in 13C-labeled proteins via scalar couplings. J. Am. Chem. Soc., 115, 11054-11055. 
36. Tjandra,N., Kuboniwa,H., Ren,H. and Bax,A. (1995) Rotational dynamics of calcium-free calmodulin studied by $15 \mathrm{~N}-\mathrm{NMR}$ relaxation measurements. Eur. J. Biochem., 230, 1014-1024.

37. Massi,F., Johnson,E., Wang,C., Rance,M. and Palmer,A.G. 3rd. (2004) NMR R1 rho rotating-frame relaxation with weak radio frequency fields. J. Am. Chem. Soc., 126, 2247-2256.

38. Daragan,V.A. and Mayo,K.H. (1997) Motional model analyses of protein and peptide dynamics using $13 \mathrm{C}$ and $15 \mathrm{~N}$ NMR relaxation. Prog. Nucl. Magn. Reson. Spectrosc., 31, 63-105.

39. Konarev,P.V., Volkov,V.V., Sokolova,A.V., Koch,M.H.J. and Svergun,D.I. (2003) PRIMUS: a Windows PC-based system for small-angle scattering data analysis. J. Appl. Crystallogr., 36, 1277-1282.

40. Svergun,D. (1992) Determination of the regularization parameter in indirect-transform methods using perceptual criteria. J. Appl. Crystallogr., 25, 495-503.

41. Jacques,D.A., Guss,J.M., Svergun,D.I. and Trewhella,J. (2012) Publication guidelines for structural modelling of small-angle scattering data from biomolecules in solution. Acta Crystallogr. D Biol. Crystallogr., 68, 620-626.

42. Guntert,P. (2009) Automated structure determination from NMR spectra. Eur. Biophys. J., 38, 129-143.

43. Shen,Y., Delaglio,F., Cornilescu,G. and Bax,A. (2009) TALOS+: a hybrid method for predicting protein backbone torsion angles from NMR chemical shifts. J. Biomol. NMR, 44, 213-223.

44. Nederveen,A.J., Doreleijers,J.F., Vranken,W., Miller,Z., Spronk,C.A., Nabuurs,S.B., Guntert,P., Livny,M., Markley,J.L., Nilges,M. et al. (2005) RECOORD: a recalculated coordinate database of 500 + proteins from the PDB using restraints from the BioMagResBank. Proteins, 59, 662-672.

45. Doreleijers,J.F., Sousa da Silva,A.W., Krieger,E., Nabuurs,S.B., Spronk,C.A., Stevens, T.J., Vranken,W.F., Vriend,G. and Vuister,G.W. (2012) CING: an integrated residue-based structure validation program suite. J. Biomol. NMR, 54, 267-283.

46. Koradi,R., Billeter,M. and Wüthrich,K. (1996) MOLMOL: a program for display and analysis of macromolecular structures. $J$. Mol. Graph., 14, 51-55.

47. Walsh,J.D., Meier,K., Ishima,R. and Gronenborn,A.M. (2010) NMR studies on domain diffusion and alignment in modular GB1 repeats. Biophys. J., 99, 2636-2646.

48. Mulder,F.A., Schipper,D., Bott,R. and Boelens,R. (1999) Altered flexibility in the substrate-binding site of related native and engineered high-alkaline Bacillus subtilisins. J. Mol. Biol., 292, 111-123.

49. Consortium,T.U. (2011) Reorganizing the protein space at the Universal Protein Resource (UniProt). Nucleic Acids Res., 40, D71-75.

50. Schumann,F.H., Riepl,H., Maurer,T., Gronwald,W., Neidig,K.P. and Kalbitzer,H.R. (2007) Combined chemical shift changes and amino acid specific chemical shift mapping of protein-protein interactions. J. Biomol. NMR, 39, 275-289.

51. Garcia de la Torre,J., Huertas,M.L. and Carrasco,B. (2000) HYDRONMR: prediction of NMR relaxation of globular proteins from atomic-level structures and hydrodynamic calculations. $J$. Magn. Reson., 147, 138-146.

52. Daubner,G.M., Clery,A. and Allain,F.H. (2013) RRM-RNA recognition: NMR or crystallography... and new findings. Curr. Opin. Struct. Biol., 23, 100-108.
53. Netter,C., Weber,G., Benecke,H. and Wahl,M.C. (2009) Functional stabilization of an RNA recognition motif by a noncanonical N-terminal expansion. RNA, 15, 1305-1313.

54. Perez Canadillas,J.M. and Varani,G. (2003) Recognition of GU-rich polyadenylation regulatory elements by human CstF-64 protein. EMBO J., 22, 2821-2830.

55. Jacks,A., Babon,J., Kelly,G., Manolaridis,I., Cary,P.D., Curry,S. and Conte,M.R. (2003) Structure of the C-terminal domain of human La protein reveals a novel RNA recognition motif coupled to a helical nuclear retention element. Structure, 11, 833-843.

56. Mackereth,C.D. and Sattler,M. (2012) Dynamics in multi-domain protein recognition of RNA. Curr. Opin. Struct. Biol., 22, 287-296.

57. Kielkopf,C.L., Lucke,S. and Green,M.R. (2004) U2AF homology motifs: protein recognition in the RRM world. Genes Dev, 18, 1513-1526.

58. Kielkopf,C.L., Rodionova,N.A., Green,M.R. and Burley,S.K. (2001) A novel peptide recognition mode revealed by the X-ray structure of a core U2AF35/U2AF65 heterodimer. Cell, 106, 595-605.

59. Selenko,P., Gregorovic,G., Sprangers,R., Stier,G., Rhani,Z., Kramer,A. and Sattler,M. (2003) Structural basis for the molecular recognition between human splicing factors U2AF65 and SF1/mBBP. Mol. Cell, 11, 965-976.

60. Corsini,L., Bonnal,S., Basquin,J., Hothorn,M., Scheffzek,K., Valcarcel,J. and Sattler,M. (2007) U2AF-homology motif interactions are required for alternative splicing regulation by SPF45. Nat. Struct. Mol. Biol., 14, 620-629.

61. Corsini,L., Hothorn,M., Stier,G., Rybin,V., Scheffzek,K., Gibson,T.J. and Sattler,M. (2009) Dimerization and protein binding specificity of the U2AF homology motif of the splicing factor Puf60. J. Biol. Chem., 284, 630-639.

62. Tsuda,K., Someya,T., Kuwasako,K., Takahashi,M., He,F., Unzai,S., Inoue,M., Harada,T., Watanabe,S. and Terada,T. et al., (2011) Structural basis for the dual RNA-recognition modes of human Tra2-beta RRM. Nucleic Acids Res., 39, 1538-1553.

63. Handa,N., Nureki,O., Kurimoto,K., Kim,I., Sakamoto,H., Shimura,Y., Muto,Y. and Yokoyama,S. (1999) Structural basis for recognition of the tra mRNA precursor by the Sex-lethal protein. Nature, 398, 579-585.

64. Lunde,B.M., Moore,C. and Varani,G. (2007) RNA-binding proteins: modular design for efficient function. Nat. Rev. Mol. Cell Biol., 8, 479-490.

65. Mackereth,C.D., Madl,T., Bonnal,S., Simon,B., Zanier,K., Gasch,A., Rybin,V., Valcarcel,J. and Sattler,M. (2011) Multi-domain conformational selection underlies pre-mRNA splicing regulation by U2AF. Nature, 475, 408-411.

66. Ule,J., Stefani,G., Mele,A., Ruggiu,M., Wang,X., Taneri,B., Gaasterland,T., Blencowe,B.J. and Darnell,R.B. (2006) An RNA map predicting Nova-dependent splicing regulation. Nature, 444, 580-586.

67. Xue,Y., Zhou,Y., Wu,T., Zhu,T., Ji,X., Kwon,Y.S., Zhang,C., Yeo,G., Black,D.L., Sun,H. et al. (2009) Genome-wide analysis of PTB-RNA interactions reveals a strategy used by the general splicing repressor to modulate exon inclusion or skipping. Mol. Cell, 36, 996-1006.

68. Kim,H.S., Kuwano, Y., Zhan,M., Pullmann, R. Jr, Mazan-Mamczarz,K., Li,H., Kedersha,N., Anderson,P., Wilce,M.C., Gorospe,M. et al. (2007) Elucidation of a C-rich signature motif in target mRNAs of RNA-binding protein TIAR. Mol. Cell. Biol., 27, 6806-6817. 